University of Louisville

ThinkIR: The University of Louisville's Institutional Repository

$12-2011$

\title{
Efficacy of child parent relationship therapy for caregivers of children with attachment problems.
}

Margaret Sergeant

University of Louisville

Follow this and additional works at: https://ir.library.louisville.edu/etd

\section{Recommended Citation}

Sergeant, Margaret, "Efficacy of child parent relationship therapy for caregivers of children with attachment problems." (2011). Electronic Theses and Dissertations. Paper 1299.

https://doi.org/10.18297/etd/1299

This Doctoral Dissertation is brought to you for free and open access by ThinkIR: The University of Louisville's Institutional Repository. It has been accepted for inclusion in Electronic Theses and Dissertations by an authorized administrator of ThinkIR: The University of Louisville's Institutional Repository. This title appears here courtesy of the author, who has retained all other copyrights. For more information, please contact thinkir@louisville.edu. 


\title{
EFFICACY OF CHILD PARENT RELATIONSHIP THERAPY FOR CAREGIVERS OF CHLDREN WITH ATTACHMENT PROBLEMS
}

\section{By}

\section{Margaret Sergeant}

M.Ed., University of Louisville, 2003

B.A., Spalding University, 1995

\author{
A Dissertation \\ Submitted to the Faculty of the \\ College of Education of the University of Louisville \\ in Partial Fulfillment of the Requirements \\ for the Degree of \\ Doctor of Philosophy \\ Department of Education and Human Development \\ University of Louisville \\ Louisville, Kentucky
}

December 2011 


\section{EFFICACY OF CHILD PARENT RELATIONSHIP THERAPY FOR CAREGIVERS OF CHILDREN WITH ATTACHMENT PROBLEMS}

\section{By}

\section{Margaret Sergeant}

M.Ed., University of Louisville, 2003

B.A., Spalding University, 1995

A Dissertation Approved on

August 26, 2011

by the following Dissertation Committee

Sam Stringfield, Dissertation Director

\section{Patrick Possel}

\section{Natalie Stipanovic}




\section{ACKNOWLEDGEMENTS}

I would like to thank the members of my committee for the time and effort each of them put into the completion of this project. I would like to especially thank my dissertation chair, Dr. Sam Stringfield, for his encouragement, feedback, and methods expertise. Dr. Patrick Possel and my friend, Dr. Nate Mitchell, provided statistical support without which completion would have been impossible. I would like to thank the caregivers and therapists at Seven Counties Services, Inc. and the teachers at Jefferson County Public Schools who so willing gave their time to complete data for this project. I would like to especially thank my parents, Barbara and Stanley Bittman, my husband, Steve, and my beautiful children, Sam and Leah. They have provided undying encouragement, patience, and understanding throughout this project that made me stick it out in the most frustrating moments. 


\title{
ABSTRACT \\ EFFICACY OF CHILD PARENT RELATIONSHIP THERAPY FOR CAREGIVERS OF CHLDREN WITH ATTACHMENT PROBLEMS
}

\author{
Margaret Sergeant
}

August 26, 2011

This dissertation examined the effectiveness of Child Parent Relationship Therapy (CPRT), a 10-week group model of Filial Therapy (FT), with caregivers of children with attachment problems. CPRT is an evidence-based treatment which is designed to strengthen relationship between caregiver and child. Research suggests that improvements in the relationship lead to changes in behavior and emotional regulation.

Therapists treating children with attachment problems at Seven Counties Services, Inc. were concerned about the lack of interventions for children with attachment problems. This study used a randomized pre-test, post-test waitlist control group design to evaluate the effectiveness of CPRT for caregivers of children identified with attachment problems by their primary therapist. The evaluation was implemented in order to determine if caregivers reported decreases in their child's internalizing and externalizing behavior problems, decrease in the number of attachment problems, and positive changes in caregiver perception of the family social environment. Teacher reports were also measured to determine if child internalizing and externalizing problems decreased. 
Six separate MANCOVAs were run to analyze three sets of dependent variables for subjects that completed the study and for all subjects originally intended to receive treatment, Intent To Treat (ITT). MANCOVA results indicated an overall treatment effect for the set of variables: attachment symptoms, externalizing problems, and internalizing problems. Post-hoc analysis indicated a significant decrease in symptoms of attachment and externalizing problems. The treatment group neared significant differences on caregiver reported internalizing problems. Although there was no overall treatment effect for family social environment, trends toward positive change on the scales of control, achievement orientation, and independence were found at the univariate level. Teacher variables were not significant. ITT analysis did not find significant differences between groups. This study showed that participation in CPRT groups had some positive results on caregiver reported variables and may be a useful alternative for children with attachment problems seeking services in Community Mental Health Centers. 


\section{TABLE OF CONTENTS}

\section{PAGE}

ACKNOWLEDGEMENTS .....................................................

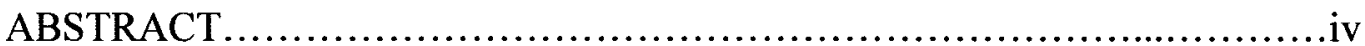

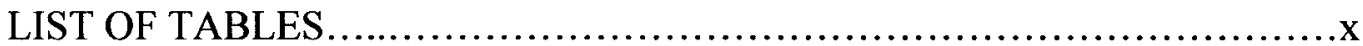

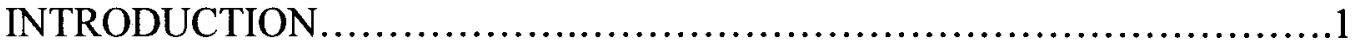

Statement of the Problem.....................................................2

Definitions and Diagnostic Criteria of Attachment.......................4

Reactive Attachment Disorder DSM/CDC Diagnostic Criteria............6

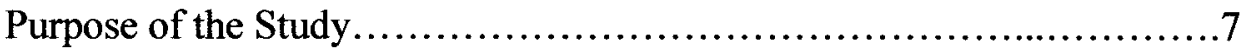

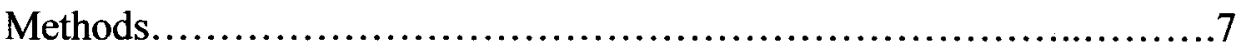

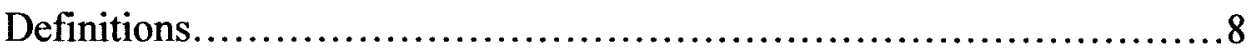

Child parent relationship therapy .............................

Filial therapy ................................................ 9

Attachment disorder.........................................

Caregiver........................................................

Community mental health center.................................10

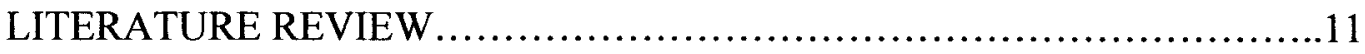

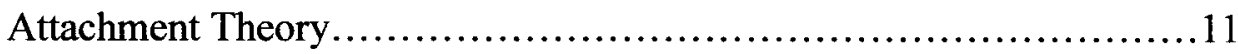

Additional research defining attachment problems................14

Attachment and trauma.........................................

Developmental perspectives in attachment theory................16 
Development of conduct problems............................16

Theory of attachment disorder as a spectrum disorder..............18

Summary of Diagnostic Criteria Controversy ..........................18

Construct validity of attachment disorder.......................21

Prevalence of attachment disorder.............................23

Psychological Problems Associated with Attachment

Disorders........................................................ 25

Literature in Treating Attachment Disorders........................28

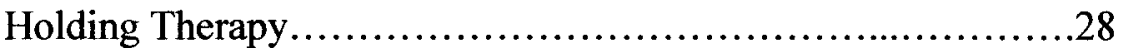

Dyadic developmental psychotherapy........................29

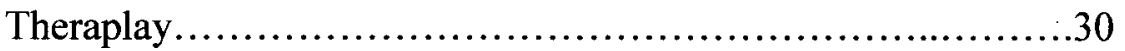

Parent child interaction therapy ..................................31

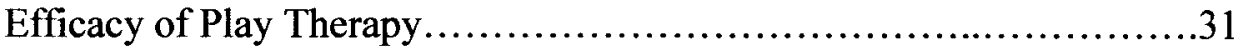

Efficacy of filial therapy...................................... 32

Purpose/Significance...................................................

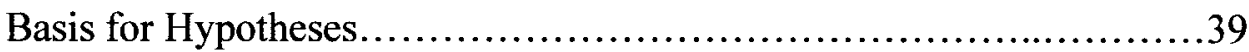

Research Questions..............................................40

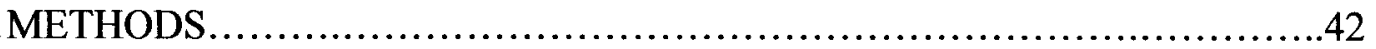

Research Hypotheses.................................................42

Population and Sample............................................44

Sample Characteristics.......................................46

Demographic information for sample......................46 


\section{Symptom and characteristics of attachment for}

$$
\text { sample }
$$

Subject Assignment.

Design .51

Treatment.

Therapist Training. 53

Measures.

Additional therapeutic interventions of subjects. 53

Behavior assessment system for children. .54

Reactive attachment disorder questionnaire. .56

Family environment scales. .56

Correlations between measures..............................57

Data Analysis 59

RESULTS. .60

Dependent Variables: PRS BASC-2 Internalizing scale, PRS BASC-2 Externalizing scale, and RAD-Q .61

Full treatment analysis. .62

Intent To Treat analysis .63

Hypothesis one...........................................66

Hypothesis three........................................66

Hypothesis five...........................................67

Dependent Variables: TRS, BASC-2 Internalizing scale and TRS, BASC2 Externalizing scale. 
Full treatment analysis.......................................68

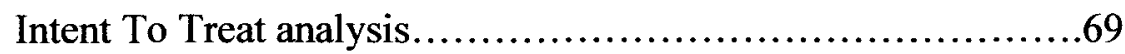

Hypothesis two................................................. 71

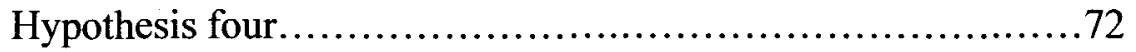

Dependent Variable: Family Environment Scales......................73

Full treatment analysis........................................73

Intent To Treat analysis................................... 75

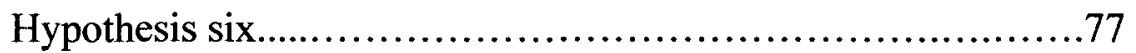

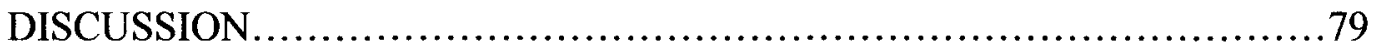

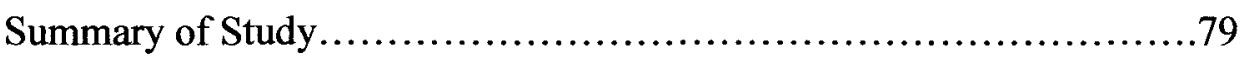

Overview and Hypotheses.......................................

Review of Methodology .......................................8 80

Findings............................................................... 81

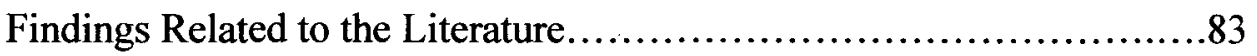

Limitations and Suggestions for Future Practice and Research............86

Implications.......................................................... 88

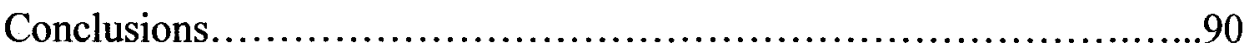

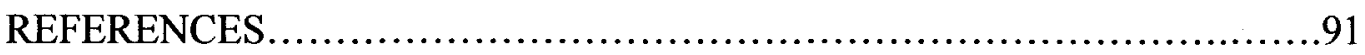

Appendix A: Therapist Checklist for Inclusion..............................103

Appendix B: Parent Information Form..................................... 104

Appendix C: Therapist Checklist for Additional Therapy Interventions.........107

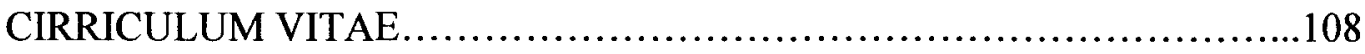




\section{LIST OF TABLES}

\section{TABLE}

PAGE

1. Sample Demographic Characteristics .47

2. Sample Characteristics of Attachment .48

3. Subject Analysis

4. Research Design

5. Additional Therapeutic Interventions of Subjects

6. Correlation Coefficients for Relations between Internalizing Behaviors, Externalizing Behaviors, Attachment Symptoms, and Family Social Environment. .58

7. MANCOVA Results for PCRT Group Treatment; BASC-2, PRS and RADQ. .63

8. Post Hoc Between Groups Univariate Analyses with Posttest Means..........63

9. MANCOVA Results for PCRT Group Treatment Intent To Treat; BASC-2,

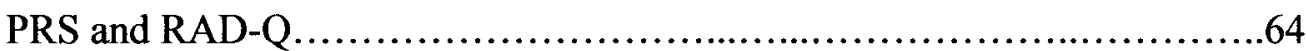

10. Post Hoc Between Groups Univariate Analyses with Posttest Means.........65

11. MANCOVA Results for PCRT Group Treatment; BASC-2, TRS................69

12. Post Hoc Between Groups Univariate Analyses with Posttest Means.........69

13. MANCOVA Results for PCRT Group Treatment Intent To Treat; BASC-2, TRS. 
14. Post Hoc Between Groups Univariate Analyses with Posttest Means..........71

15. MANCOVA Results for PCRT Group Treatment; FES ...................74

16. Post Hoc Between Groups Univariate Analyses with Posttest

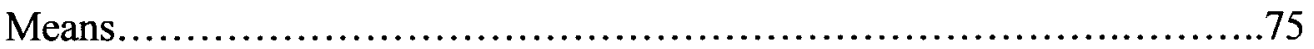

17. MANCOVA Results for PCRT Group Treatment Intent To Treat;

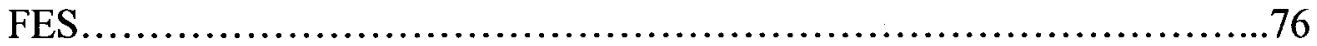

18. Post Hoc Between Groups Univariate Analyses with Posttest Means..........77 


\section{CHAPTER I}

\section{INTRODUCTION}

The purpose of this study was to determine if Child Parent Relationship Therapy (CPRT, Landreth \& Bratton, 2006), a 10-session model of Filial Therapy (FT) is an effective intervention for treating caregivers of children with attachment problems. FT trains caregivers to become the therapeutic agent (i.e., the caregiver is present during each session and will lead most play therapy sessions) during play sessions with their children. FT is consistent with attachment theory, attachment literature, and has been found successful with many different populations of children(Boris \& Zeanah, 2005; Files-Hall \& Reddy, 2005; Hanson \& Spratt, 2000; Haugaard \& Hazan, 2004; Minde, 2003; O’Connor \& Zeanah, 2003; Ray, 2006; Ryan, 2004; Sheperis, et. al, 2003). CPRT is a group model of FT intended to provide education and support for caregivers giving them the knowledge and skills to implement play sessions in the home. This study focused on changes in (a) internalizing problems of the child (i.e., those behaviors that are directed inward, such as anxiety, depression, and somatic complaints), (b) externalizing problems of the child (i.e., those behaviors that are directed outward, such as, aggression, hyperactivity, and conduct problems), (c) the expression of attachment disorder symptoms present, and (d) the family social environment as perceived by the caregiver. The research design was a quasi-experimental design with a pre-test/post-test waitlist control group incorporating random assignment. Therapists referred subjects for 
participation in the study based on specific criteria of attachment problems (see Appendix A). Inclusion criteria were identification of three or more symptoms or behaviors of attachment based on criteria from Appendix A. Following the referral and selection process, the subjects were randomly assigned to the control or treatment groups. Child behaviors were measured using the Teacher Rating Scale (TRS) and Parent Rating Scale (PRS) from the Behavior Assessment System for Children, $2^{\text {nd }}$ Edition (BASC-2, Reynolds \& Kamphaus, 2004), symptoms of attachment were measured using the Randolph Attachment Disorder Questionnaire (RAD-Q, Randolph, 1999), and family members' perceptions of their social environment were measured using the Family Environment Scale (FES, Moos \& Moos, 1994).

\section{Statement of the Problem}

There is a lack of empirically based interventions for children with attachment disorders. Many professionals are introducing and practicing assessment methods and treatment strategies that have not been empirically supported, including some that may be potentially harmful (Boris \& Zeanah, 2005; Files-Hall \& Reddy, 2005; Hanson \& Spratt, 2000; Haugaard \& Hazan, 2004; Minde, 2003; O'Connor \& Zeanah, 2003; Ray, 2006; Ryan, 2004; Sheperis, et. al, 2003). In 1999, Boris and Zeanah suggested, "As we move forward on characterizing disturbances of attachment, we must begin to consider interventions that address these clinical syndromes" (pg. 2). It is vital that we begin the

process of analyzing treatment models that are based in attachment theory and determine if suggested treatment models are valid for use with caregivers of children who exhibit symptoms of attachment disorders. 
Attachment disorder is often diagnosed in children who have suffered abuse and neglect indicating that treatment for children with attachment problems should follow guidelines for children with a history of abuse or neglect. One such governing body that makes recommendations concerning children who suffer abuse is the Professional Society on the Abuse of Children (APSAC) task force, organized by the American Psychological Association (Chaffin et. al, 2006). The guidelines suggested by the APSAC for the treatment of children with attachment problems includes (a) drawing from a foundation in attachment theory, (b) including caregivers in treatment and/or ensuring environmental stability, (c) guaranteeing child safety, (d) incorporating patience and sensitivity with the child, (e) consistency of treatment, and (g) a focus on nurturance of the child. One known treatment that meets these guidelines is FT which is recommended for use with children with attachment disorder (AD) and Reactive Attachment Disorder (RAD) in The Child Psychotherapy Treatment Planner (Jongsma, Peterson, McInnis, \& Bruce, 2006), a treatment manual considered a gold standard. Although they are making this recommendation, their recommendation is not based on research. CPRT, a group model of FT, is compatible with recommendations for children with attachment problems (Boris \& Zeanah, 2005; Files-Hall \& Reddy, 2005; Hanson \& Spratt, 2000; Haugaard \& Hazan, 2004; Minde, 2003; O’Connor \& Zeanah, 2003; Ray, 2006; Ryan, 2004; Sheperis, et. al, 2003). Additionally, CPRT meets the criteria outlined by the APSAC task force (Chaffin et. al, 2006), and is congruent with attachment theory literature (Bowlby, 1968, 1988; Ainsworth, 1978, 1989; Main \& Soloman, 1986). CPRT also meets the recommendations from attachment literature that stipulate non-coercive therapy, the inclusion of parents and caregivers in treatment, providing an intervention 
that is goal-directed and behavioral, and having a strong foundation in attachment theory (Chaffin et. al, 2006).

\section{Definitions and Diagnostic Criteria of Attachment}

Because understanding attachment theory is crucial to understanding attachment disorder, a review of attachment theory is presented to provide the reader with a background of the theoretical perspectives of attachment. The clinical diagnosis/terminology of attachment problems is presented. It should be noted that current clinical diagnoses related to problems of attachment lack a focus on attachment theory, primarily lacking a focus on the relationship between a child and his/her caregiver. Diagnoses are still considered to have developed as a result of work conducted by early developmental theorists. Bowlby defines attachment as the ability to form adaptive relationships (1968). This ability in infancy refers to forming bonds with the primary caregiver and later refers to a person's ability to form other significant relationships (Bowlby, 1968). Attachment disorder is a term that is used broadly to describe a failure to form adaptive attachment relationships. Components of the disorder include disturbance of mood, behavior, and social relationships arising from a failure to form normal attachments to primary care giving figures in early childhood (Bowlby, 1968). According to attachment theory, a child's capacity for emotional regulation and their ability to form meaningful relationships develops from early child-caregiver bonds (Bowlby, 1968). Secure Attachment is described as a pattern of relatedness between a child and the primary caregiver that is consistent with healthy development (Ainsworth, Blehar, Waters, \& Wall, 1978). According to Ainsworth et al. (1978) secure attachment is evident when a child feels free to explore his/her environment, is not significantly distressed during 
caregiver absence, prefers the parent or caregiver to strangers, and contact initiated by the parent is readily accepted. An available parent or caregiver who is responsive when needed helps develop a secure attachment. (Bowlby, 1988) Insecure Attachment is described as the lack of a bond forming between infant and caregiver. An insecure attachment is characterized by a lack of caregiver-consistency, caregiver-responsiveness and trust (Ainsworth, et. al, 1978). There are two types of insecure attachment (i.e., anxious-avoidant attachment and ambivalent attachment). A child that exhibits avoidant or anxious-avoidant attachment shows few or no signs of distress at the caregiver's departure, followed by a willingness to explore, and little to no visible response to the caregiver's return. (Ainsworth et. al, 1978) This results in a failure of the child forming a secure attachment and the child demonstrates uncertainty that the parent or caregiver will be responsive or helpful when needed (Bowlby, 1988). Ambivalent attachment, sometimes referred to as resistant attachment, is characterized by a child exhibiting sadness on the caregiver's departure, demonstrates approachability and acceptance of comfort by a stranger, demonstrates ambivalence when the caregiver returns, exhibits signs of anger and/or reluctance to being comforted and demonstrates a quick return to play. (Ainsworth et. al, 1978) Once again, there is a failure to form a secure attachment with the primary caregiver and the child appears to have no confidence that the caregiver will be responsive and helpful when needed. Disorganized Attachment, first introduced by Main and Soloman (1986) consist of a lack of clear attachment behavior. Behaviors are described as a combination of insecure attachment behaviors, including avoidance and resistance. Children with disorganized attachment are described as exhibiting dazed behavior, seeming either confused or apprehensive in the presence of a caregiver. The 
diagnoses for attachment problems are based in the theory of attachment presented here but are inadequate in clearly defining the difficulties of these children.

\section{Reactive Attachment Disorder DSM/CDC Diagnostic Criteria}

Current criteria for Reactive Attachment Disorder (RAD) as defined by the American Psychological Association's DSM-IV TR (2000) are characterized by "markedly disturbed and developmentally inappropriate social relatedness in most contexts." This disturbance "must be present prior to age five and cannot be accounted for by developmental delay" (DSM-IV TR, 2000) Two types of RAD described in the DSM-IV TR (2000) are Inhibited Type and Disinhibited Type. Inhibited Type is described as, "when children may appear detached, unresponsive, inhibited or reluctant to engage in age-appropriate social interactions," and Disinhibited Type is described as, "when children with RAD may be overly and inappropriately social or familiar, even with strangers," (DSM-IV TR, 2000). Criteria also state that, "pathogenic care must be evident" (DSM-IV TR, 2000). This is described by the DSM-IV TR (2000) as, "persistent disregard of the child's basic emotional needs, basic physical needs, or repeated changes in primary caregivers that lead to prevention of stable attachments."

The World Health Organization in the International Classification of Diseases (ICD-10, 1992) describes approximately the same criteria with F94.1, Reactive Attachment Disorder of childhood matching most closely with Inhibited type and F94.2, Disinhibited attachment disorder of childhood matching the Disinhibited Type. In the ICD-10, it is referred to as "RAD" for the inhibited form, and disinhibited attachment disorder, or "DAD" for the disinhibited form. In the DSM-VI-TR, it is referred to as "RAD" and a distinction is made between inhibited and disinhibited types. Both 
organizations indicate problems across situations and relationships and do not maintain a primary focus on the relationship with the primary caregiver (DSM-IV TR 2000; ICD-10, 1992).

\section{Purpose of the Study}

The purpose of this study was to determine if CPRT, a 10-session model of FT is effective in treating caregivers of children with attachment disorders. FT is recommended for use with children with RAD and AD in The Child Psychotherapy Treatment Planner (Jongsma, 2006), considered the gold standard in treatment manuals. FT, specifically the CPRT model, was chosen for this study based on a good fit with suggestion from attachment literature (Boris \& Zeanah, 2005; Files-Hall \& Reddy, 2005; Hanson \& Spratt, 2000; Haugaard \& Hazan, 2004; Minde, 2003; O'Connor \& Zeanah, 2003; Ray, 2006;

Ryan, 2004; Sheperis, et. al, 2003), as well as being pragmatic and conducive to a Community Mental Health Center (CMHC) setting making it widely available to families of all socioeconomic strata. The model also matches well with the recommendations presented by the Professional Society on the Abuse of Children (APSAC) task force indicating that the "first-line services for children described as having attachment problems should be founded on the core principles of attachment theory, including caregiver and environmental stability, child safety, patience, sensitivity, consistency, and nurturance" (Chaffin et. al, 2006).

\section{Methods}

The study employed a quasi-experimental pre-test post-test design with a waitlist control group in an effort to determine efficacy of CPRT for caregivers of children with attachment problems. The study included caregivers of children between the age of six 
and ten who were receiving services in an urban $\mathrm{CMHC}$. Initial recruitment of subjects was referral for treatment by the child's primary therapist based on possession of three or more characteristics from the list of behaviors and negative symptoms common to children with attachment problems (see Appendix A). Therapist providing treatment for the group had extensive training in Landreth and Bratton's Child Parent Relationship Therapy (CPRT, 2006) to include a minimum of eight hours of child centered play therapy training and forty-five hours of training directly related to the CPRT model. Outcomes for the proposed study are based on several measures. Internalizing and Externalizing problems outcomes were measured using the Teacher Rating Scales (TRS) and Parent Rating Scales (PRS) from the Behavior Assessment System for Children, $2^{\text {nd }}$ Edition (BASC-2, Reynolds \& Kamphaus, 2004), attachment symptoms were measured by the Randolph Attachment Disorder Questionnaire (RAD-Q; Randolph, 1999), and parent child relationship factors were measured by the Family Environment Scale (FES; Moos \& Moos, 1994). Data for the treatment and control groups are analyzed with SPSS using six separate MANCOVAs to test the statistical significance between groups on the Externalizing and Internalizing problem scales on the TRS and PRS of the BASC-2, the RAD-Q, and the FES. To examine treatment effect, analysis was completed to compare subjects who completed group services to waitlist control subjects and Intent To Treat (ITT) analysis was conducted to provide a more conservative measure of treatment effects.

\section{Definitions}

\section{Child parent relationship therapy.}

Child Parent Relationship Therapy (CPRT) is a ten session filial therapy model designed by Landreth $\&$ Bratton (2006). It is a structured system of didactic instruction, 
demonstration of play sessions by therapists, videotaped practice play sessions by caregivers, and supervision in a supportive atmosphere in a 2-hr weekly group format. The initial training for caregivers provided education and practice in skills for conducting play sessions in the home. Skills included setting up a play session, how to allow children to guide play, how to identify their child's feelings, how to address feelings in a supportive manner, how to set boundaries in a supportive and therapeutic manner, and communication techniques that build relationships. After initial training, videotapes are reviewed in groups and feedback is provided to build on skills and more intensive training is implemented for skills mentioned above.

\section{Filial therapy.}

Filial Therapy (FT) is an alternative method for treating emotionally disturbed children in which the parent is used as an ally in the therapeutic process. The parent becomes the child's primary therapeutic agent (Ginsberg, 1976).

\section{Attachment disorder.}

Attachment disorder (AD) is defined as a failure to form normal attachments with a primary caregiver in early childhood resulting in disorders of mood, behavior, and/or social relatedness.

\section{Caregiver.}

Caregiver is defined as the person or persons who are primarily responsible for the care of the child. This may include parents, adoptive parents, custodial grandparents or other relatives, or foster parents. 


\section{Community mental health center.}

Community Mental Health Center (CMHC) is an organization that provides a variety of mental health treatment services, and sometimes substance abuse treatment services, to people who live within certain geographic boundaries, often a single county, or group of adjacent counties. 


\section{CHAPTER II}

\section{LITERATURE REVIEW}

Attachment theory is reviewed to provide a basis for the importance of creating an attachment with the primary caregiver and to provide background for research based in attachment theory. Additionally, chapter II reviews the controversy surrounding diagnosis of Reactive Attachment Disorder (RAD), the concept of Attachment Disorders (AD), and reviews the body of research that begins to address the construct validity of $\mathrm{RAD}$ and $\mathrm{AD}$. Literature is introduced that reviews the psychological problems associated with $\mathrm{AD}$ to provide a basis for the need for therapeutic interventions. Efficacy of prior treatments for $\mathrm{AD}$ and the efficacy of filial therapy are reviewed to support use of such a treatment in the current study. Research questions addressed are also presented.

\section{Attachment Theory}

Attachment is the bond created between an infant and the primary caregiver and how this attachment develops has a significant effect on the development of a child. (Bowlby, 1988) Origins in attachment theory are less than fully adequate in defining attachment problems because they focus on healthy development and do not provide a clear list of symptoms that characterize children with attachment problems. However, it is necessary to understand attachment theory when attempting to categorize children with attachment problems and/or disorders. 
The current diagnosis of RAD lacks an emphasis on the relationship with the primary caregiver and many professionals believe it should align better with attachment theory. (Zeanah, 1996; Richters \& Volkmar, 1994; Hanson \& Spratt, 2000) In the history of attachment theory, the terminology used to describe children with attachment problems is confusing and convoluted due to the number of different terms used to describe similar styles of attachment.

It is imperative to review the work of John Bowlby because it is clear that his work in attachment theory continues to influence attachment theorists today. Research using the "Strange Situation" by Ainsworth and colleges (1978) supports many of Bowlby's original theories and has a significant influence current attachment theory. John Bowlby (1988) emphasized the biological need to form attachments. This innate tendency to form social interactions, predominately with the primary caregiver as a child, is present to facilitate survival. He described the relationship as a secure base for children as crucial in helping them to form attachments in subsequent relationships during childhood and later in life. Additionally, early intervention is believed to be necessary to prevent the formation of disturbed attachment behaviors and interactions.

Bowlby (1988) indicates that human nature includes an innate "urge to explore the environment, to play, and to take part in varied activities with peers." (p.3) Additionally, Ainsworth, et al. (1978) published landmark studies that added significant research in support of Bowlby's original theory. Ainsworth et.al (1978) proposed three types of attachment patterns which included secure, anxious-avoidant, and ambivalent. Main and Soloman (1986) later identified a pattern of disorganized attachment. Patterns of attachment were studied using a method referred to as the strange situation. Study 
methods looked at associations between mother's style of parenting and infant attachment styles, specifically the reaction of the child to separation from the mother and interaction with strangers. They found secure attachment related to social abilities later with other children and adults not the parents, increased compliance with parental demands, and effective emotional regulation. (Ainsworth et. al, 1978) "Normative findings substantially support Bowlby's descriptions of the organization and function of infant attachment behavior" (p.95).

The infant research of Ainsworth and her colleagues provides support for the original theories introduced by Bowlby and have influenced definitions and diagnoses related to attachment. Theoretical background provided by Bowlby and the studies by Ainsworth lead to the following description of attachment patterns. Secure Attachment is evident when a child feels free to explore their environment, is not significantly distressed during caregiver absence, prefers parent or caregiver to strangers, and readily accepts contact initiated by a parent (Ainsworth et. al, 1978). Bowlby (1988) describes a pattern of relatedness with the primary caregiver that is consistent with healthy development. Avoidant attachment is characterized by a child (Ainsworth et. al, 1978) who shows few or no signs of distress at the caregiver's departure, followed by a willingness to explore, and little to no visible response to the mother's return. Avoidant or anxious-avoidant attachment is a failure to form a secure attachment and the child becomes uncertain if the parent or caregiver will be responsive or helpful when needed (Bowlby, 1988). Ambivalent attachment is characterized by a child (Ainsworth et. al, 1978) who exhibits sadness on the caregiver's departure, is approachable and even comforted by a stranger, is ambivalent when the caregiver returns, exhibits signs of anger 
and/or is reluctant to being comforted and will quickly return to exploration. Ambivalent attachment, sometimes referred to as resistant, is a failure to form a secure attachment and the child has no confidence that the caregiver will be responsive and helpful when needed.

In addition to the types proposed by Ainsworth (1978), Main and Soloman (1986) identify the subtype Disorganized Attachment. Children identified as having disorganized attachment exhibit dazed behavior, seeming either confused or apprehensive in the presence of a caregiver. They describe disorganized attachment as a lack of clear attachment behavior; a mix of insecure attachment behaviors, including avoidance and resistance.

\section{Additional research defining attachment problems.}

Many theorists have contributed to or expanded the theories first introduced by Bowlby and Ainsworth. Often the terminology has changed or categories are expanded; however, theory continues to be heavily influenced by origins in attachment and theorists continue to provide support for the importance of the child's relationship with a primary caregiver. Lieberman and Pawl (1988) present three types of attachment disorders. Nonattachment included those children with no opportunity to form attachments resulting in severe impairment in ability to form relationships, Anxious/Avoidant attachment described an infant that had the opportunity to form a relationship although it consisted of conflicts in physical and emotional availability, and Disrupted attachment which includes infants who experience separation and loss with attachment figures. In 1993, Zeanah, Mammen, and Lieberman proposed five types of attachment disorders to include nonattachment, indiscriminate, inhibited, aggressive, and role-reversal. Nonattachment is 
the failure to develop an attachment with a primary caregiver. Nonattachment appears to be closely related to Main and Soloman's category defined as disorganized attachment. Indiscriminate attachment is the failure to use the caregiver as a secure base and can be characterized by indiscriminate friendliness or reckless and accident-prone behavior. Inhibited is characterized by excessive clinginess or compulsive compliance. Aggressive attachment is described as anger and aggression as pervasive features of the relationship with the primary caregiver and may also include anger and aggression directed at self and others. Role-reversal attachment indicates that the child will assume the caregiver role and exhibit controlling behaviors with caregivers who may be displayed as bossy and hostile or as caregivers.

Rutter, Kreppner, and Sonuga-Barke (2009) indicate tendencies to interpret patterns of attachments in relation to differences in security/insecurity. They reviewed research as it relates to concepts of attachment in infancy and later childhood, disorganized attachment, inhibited attachment disorder, and disinhibited attachment. They suggest that, "it is seriously misleading to view all of these patterns through the lens of security/insecurity. This heterogeneity in social relationship features necessarily has implications for the assessment measures for social relationships that need to be used."

\section{Attachment and trauma.}

Children who experience trauma are at greater risk for AD. Levy \& Orlans (1998) and Becker-Weidman (2006) focus their work on children who have experience trauma and are categorized with AD. Levy \& Orlans (1998) focus on attachment and trauma and categorize children as having either a secure attachment similar to Bowlby's (1968) definition of secure attachment or disrupted attachment which appears to include children 
with anxious, avoidant, and disorganized attachment classifications. Disrupted

attachment can be the result of many different events that may include prenatal drug and alcohol exposure, physical or emotional neglect, physical or emotional abuse, sexual abuse, violence, multiple caregivers. They report disrupted attachment places a child at risk for many serious problems to include low self-esteem, inability to handle stress and adversity, lack of self-control, alienation and opposition with authority figures, aggression and violence, antisocial attitudes and behaviors, and lack of empathy and remorse. Becker-Weidman (2006) focuses his work on children who have suffered serious maltreatment and have been removed from the primary caregiver. He categorizes these children as having trauma-attachment disorders and indicates they are at high risk for severe psychiatric problems.

\section{Developmental perspectives in attachment theory.}

Attachment theory is important in understanding child development (Carmen \& Huffman, 1996). Hughes (1998) takes a developmental approach, but continues to place emphasis on the relationship with the primary caregiver in developing skills in affect modulation and attunement, behavioral organization, cognitive capacity and cognitive differentiation. His theory describes a development of attachment that progresses through the first two years of life. Disruptions at various stages of the development of attachment will produce a variety of symptoms that include a lack of affective attunement and excessive shame.

\section{Development of conduct problems.}

Greenburg, Speltz, and DeKlyen (1993) indicate that the attachment relationship is one of four factors that contribute to the development of behavior disorders. Family 
stress, discipline, and temperament or neurobiological factors are etiological factor; however, they view the development of the attachment relationship as the most important risk factor in the predication of later behavior problems, predominately the diagnosis of Oppositional Defiant Disorder (ODD). However, poor attachments have also been found to lead to more serious delinquency and the diagnosis of Conduct Disorder $(\mathrm{CD}$, Loeber, Laney, \& Thomas, 1991). Lyons Ruth $(1993,1996)$ also found evidence that early attachment problems produced a greater risk for later hostile and aggressive behavior. Fox \& Pancake (1983) provide research that supports the developmental perspective of attachment theory in a study of 40 children between 47 and 60 months, drawn from a high risk sample. They indicate that children with secure attachments demonstrate less emotional dependence on the preschool teacher, are more independent, and sought assistance appropriately. Children that were classified with anxious attachment demonstrated an over dependence on the teacher and exhibited more distress upon separation from mother. Children classified with avoidant attachment exhibited low levels of contact-seeking, and were described as seemingly withdrawn.

Sroufe, Fox, and Pancake (1983) presented findings from a longitudinal study that focused on relationships with primary caregivers for 20 years. He found that depressed mothers that exhibit low interest in their infants were more likely to have children categorized with anxious attachment at one year. When tested at age four and five, children with secure attachments produced higher scores on measures of social skills, friendships, empathy, leadership, self-esteem, and resilience. Children with avoidant attachment patterns were described by Sroufe as devious, manipulative, enjoyed distress of others, and had trouble sharing. By ten years old, boys in this category were aggressive 
and exhibited deviant behaviors typical of conduct disorder and girls were described as more likely to internalize and become depressed. These patterns were reported to have continued into adolescence.

\section{Theory of attachment disorder as a spectrum disorder.}

Boris and Zeanah (1999) are currently leading the field in an attempt to more accurately categorize children with attachment problems. They suggest that attachment problems be defined along a continuum with secure attachments being the absence of a disorder. Additional categories included in the continuum include; Insecure (avoidant or ambivalent) Attachment, Disorganized Attachment, Secure Base Distortions, and Disorders of Non-Attachment or Reactive Attachment Disorder (RAD). The theory that attachment problems be placed on a continuum is based on a series of articles in a special edition of the Infant Mental Health Journal. O'Connor and Zeanah (2003) discuss both sides of the suggestion of placing attachment disorder and attachment disorganization on a spectrum. One advantaged mentioned is that placing both on the same continuum would link attachment disorders to the attachment research of Bowlby, Ainsworth, and others. Attachment problems as a spectrum disorder (Minde, 2003) are proposed to encompass the severity of clinical symptoms.

\section{Summary of Diagnostic Criteria Controversy}

The studies presented by Boris and Zeanah $(1999,2003)$ indicate a need for continuing to work toward accurately defining attachment. O'Connor (2002) indicates that further research is needed to determine the relationship between theory, $\mathrm{AD}$, and RAD. It is important to consider what we know about how children form attachments 
and to maintain a distinction between theory and research. Del Carmen and Huffman (1996) review the importance of incorporating attachment and developmental theories in understanding psychopathology. The need for a clear diagnosis to identify clients and drive treatment recommendations continues to exist; however, theory and research indicate that the construct of $\mathrm{AD}$ exists and that alternative treatment options are needed. Given this, much of the literature written on the treatment of "attachment disorder" may or may not reflect the diagnostic version of the construct.

It is prevalent throughout the literature that the current definitions for attachment problems do not adequately define problems with attachment and that the criterion for RAD included in the DSM is not clinically practical for the assessment of child pathology. (Boris, Hinshaw-Fuselier, Smyke, Scheeringa, Heller, and Zeanah, 2004; Boris and Zeanah, 2005, Chaffin, Hanson, Saunders, Nichols, Barnett, Zeanah, Berliner, Egeland, Newman, Lyon, LeTourneau, and Miller-Perrin, 2006, Haugaard and Hazan, 2004; Marvin and Whelan, 2003; O'Connor and Zeanah, 2003; Sheperis, Doggett, Hoda, Blanchard, Renfro-Michel, Holdiness, and Schlagheck, 2003; Zeanah, 1996) Zeanah (1996) presents a detailed summary of the criticisms of the diagnosis as it is described in the DSM-IV and ICD-10. Criticisms include views that the current clinical diagnoses better represent maltreatment syndromes than disorders of attachment and that maltreatment is neither "necessary nor sufficient" to make the diagnosis. Additional criticisms indicate diagnosis should be more focused on attachment with a primary caregiver than social functioning. The age criterion is questioned due to a lack of evidence that symptoms must be present prior to the age of 5 . A lack of evidence exists that indicates children with cognitive delays or mental retardation should not be 
diagnosed with attachment disorders. Richters and Volkmar (1996) indicate that diagnostic requirements with a focus on social behavior is problematic, especially the requirement that problems with social behavior being evident across social relationships. While children with attachment problems often develop problems across social relationships, the primary problem in attachment occurs with the primary caregiver.

There is controversy surrounding the need for pathogenic care as a basis for diagnosis and with defining pathogenic care as grossly maltreated. Many researchers feel that there is a tendency to diagnose any child with RAD if abuse is present (Richters \& Volkmar, 1996; Hanson \& Spratt, 2000). Hanson and Spratt (2000) indicate that many children exhibit behavioral characteristics of attachment problems that do not have a history of gross pathogenic care. There is evidence for the development of AD when severe physical abuse is not present (Rutter, 1997). O'Connor and his colleagues (2000, 2003) compared children adopted in the United Kingdom who they believe did not experience deprivation to children adopted in Romania who experienced deprivation. The findings suggest that attachment disturbances, defined as similar to what we consider Reactive Attachment Disorder, are found in children who are removed from the primary caregivers but did not suffer early deprivation. These findings raise questions about the necessity of pathogenic care in determining a clinical case of Reactive Attachment Disorder. This supports the notion that pathogenic care is one criterion, and that item alone does not determine the presence of the diagnosis. However, children who experience pathogenic care are at greater risk for developing problems of attachment. Zeanah (1996) indicates that "focusing on attachment behaviors rather than on maltreatment avoids the problem of attempting to determine what constitutes emotional 
maltreatment, recognizes that attachment is only one among several possible sequela of maltreatment, and recognizes that maltreated children have diverse outcomes" (p.46).

There is also concern about the usefulness of the DSM criteria which indicates that symptoms must be present prior to age five. (Hanson \& Spratt, 2000) In older children, specific knowledge of early years of life is often unavailable or obscure. While it is evident that problems of attachment can be formed during the first years of life (Bowlby, 1968, 1988; Ainsworth, 1978, 1989; Main \& Soloman, 1986; Boris \& Zeanah, 2005; O'Connor \& Zeanah, 2003) more research is needed concerning the trajectory of the disorder. It is possible that "prior to age 5" criteria may influence clinicians to avoid diagnosis in children older than five regardless of attachment history. There may be evidence to suggest pathogenic care was present in early childhood, but there may not be sufficient evidence that the child was symptomatic. This is especially true in cases where the caregiver was significantly neglectful and did not report or monitor any unusual behaviors due to their own perception of neglect.

\section{Construct validity of attachment disorders.}

Despite the difficulties surrounding the diagnostic criteria for RAD, the notion that attachment disorder is a valid construct is found throughout literature. Neil Boris and his colleagues have begun a body of literature that attempts to categorize attachment disorders and provide validity for diagnoses. Boris et al. $(1998,2004)$ found construct and face validity for a diagnosis of attachment disorder in high-risk samples using an interview procedure and observational data. Boris et al. (1998) studied the reliability of different sets of criteria for attachment disorders. He attempted to find construct validity 
for the DSM diagnosis of RAD and for definitions of the construct of $\mathrm{AD}$. Interrater reliability among four experienced clinicians were reported for the DSM diagnostic criteria for RAD, for definitions of nonattachment, and for definitions of disordered attachment and disrupted attachment in review of historical data for 48 consecutive clinical case summaries. Researchers reported pair wise kappas for each definition and found that nonattachment with emotional withdrawal $(0.84)$ and nonattachment with indiscriminate sociability $(0.81)$ had the highest interrater reliability and are considered to have acceptable reliability, while the DSM criteria for Reactive Attachment DisorderInhibited (0.46) and Reactive Attachment Disorder-Indiscriminate (0.36) had the lowest interrater reliability. Scores for alternative definitions included Disordered Attachment with inhibition (0.70), Disordered attachment with self-endangerment (0.75), Disorder Attachment with role reversal (0.53), and Disruptive Attachment Disorder (0.66). Interrater reliability for diagnosis of no attachment disorder was 0.68 . Children participating in the current study are under age three and it may be hard to replicate these results without observations while the child is young. However, it does imply that a strong historical interview is appropriate for use with experienced clinicians. Boris, et al (2004) studied the validity of establishing a diagnosis for attachment disorders in a highrisk sample of preschool age children placed in foster care for abuse or neglect and homeless youth. With a comparison group incorporated from a Head Start program, they found evidence that interview and observation could be implemented to diagnosis attachment. There was no validity for the diagnosis of attachment disorder with role reversal. Construct and face validity were found for the definition provided by the DSMIV and the ICD-10. Proposed concepts of attachment disturbance that include attachment 
disorder with self-endangering, attachment disorder with inhibition, and attachment disorder with compulsive compliance were also found to have face validity and construct validity. There was high interrater reliability (Kappas, $0.62-0.74$ ) for the presence of attachment disorder. Thirty-six of 69 children were diagnosed with attachment disorder, indicating that the presence of attachment disorder in high-risk samples may be more prevalent than is indicated in previous research. These studies imply that a strong historical interview by an experienced clinician is appropriate for use in the diagnosis of attachment problems. While there is still a great deal of controversy concerning the diagnosis and construct validity of Reactive Attachment Disorder and definitions of attachment disorder, researchers and clinicians agree that the attachment bond or lack of attachment will impact a child's behavior, emotions, future relationships, and value system.

\section{Prevalence of attachment disorders.}

There is a lack of research that unequivocally establishes the prevalence of attachment disorders; however, there is evidence that it can be diagnosed in community mental health agencies and that $\mathrm{AD}$ is more prevalent than RAD is thought to be. The DSM-IV-TR (2000) indicates that RAD is uncommon. Zeanah and Smyke (2008) indicate that reactive attachment disorder (RAD) may be identified reliably in only a minority of children being raised in severely neglectful environments. There is very little research into the epidemiology of $\mathrm{RAD}$ or $\mathrm{AD}$. The controversy over diagnostic criteria and the lack of valid measures for diagnosis makes it more difficult to diagnose; however, the Randolph Attachment Disorder-Questionnaire (RAD-Q, Randolph, 1999) is often used in conjunction with other measures to provide a diagnosis of RAD and $A D$ 
(Sheperis et. al, 2003) Morgan (2000) studied a sample of 662 clients in a community mental health center and found the following prevalence statistics in this population. The study found that $0.18 \%-1.6 \%$ clients in Seven Counties Services-Community Mental Health Center (SCS-CMHC) diagnosed RAD $(\mathrm{N}=662)$. When using the Randolph Attachment Disorder questionnaire, 23\% clients in SCS-CMHC identified as having attachment disorders. Additionally, Morgan found that $10 \%-25 \%$ of clients in SCSCMHC with attachment problems as measured by the RAD-Q.

While there is some controversy regarding the connection between pathogenic care and attachment problems, it appears clear that children who have experienced childhood trauma are at greater risk for attachment disorder. Children who have suffered repeated trauma at an early age appear to have increased risk for mental disorders and poor physical health. (Levy \& Orlans, 1998) Many children who are victims of abuse and/or neglect are removed from the home during investigation, which places them at greater risk for problems related to creating and maintaining attachments with the primary caregiver. The U.S. Department of Health and Human Resources (McMillan et. al, 2004) indicates there are 872,000 victims of abuse and neglect a year with children birth to three years having the highest incident rate. Nineteen percent of these children were removed from their primary caregivers during investigations into child abuse and neglect and an additional $4 \%$ of non-victims were removed. Theoretically, children who are removed from the home, have multiple care givers, and/or suffer abuse or neglect are at risk for developing attachment problems. 


\section{Psychological Problems Associated with Attachment Disorders}

There has been a great deal of research that indicates that children with attachment problems or attachment disorders are at a greater risk for developing later psychological problems. (Bowlby, 1988; Carlson, 1990, 1998; Rosenstein \& Horowitz, 1996; Greenburg, Speltz, \& DeKlyen, 1993; Greenburg, 1998; Hall and Geher, 2003; Levy \& Orlans, 1998; Loeber, Lahey, and Thomas, 1991; Lynam, 1996; Lyons-Ruth, Alpern \& Repocholi, 1993; Lyons-Ruth, 1996; Schreiber and William, 1998; Sroufe, Schwartz and Davis, 2006) Children diagnosed with Attachment Disorders are at higher risk for development of oppositional and conduct disorders (Greenburg, Speltz, \& DeKlyen, 1993; Levy \& Orlans, 1998, Lyons-Ruth, 1996), and adolescent psychopathology (Carlson, 1998; Rosenstein \& Horowitz, 1996). Lyons-Ruth, Alpern \& Repocholi, 1993 indicate Disorganized Infant Attachment and Maternal Psychosocial Problems predict hostile and aggressive behavior at age 5. There are long-term implications for the development of dissociative symptoms in childhood and adolescence associated with trauma (Carlson, 1990). Insecure or disorganized attachment is thought to be a risk factor for the later development of psychopathology (Bowlby, 1988) Hall and Geher (2003) indicate many behaviors are associated with RAD to include stealing, lying, cruelty to animals and people, avoidance of eye contact, destruction of property, gorging of food, abnormal speech patterns, inappropriate sexual behavior, role reversal, and overactivity. Levy (1998) describes RAD as inability to form meaningful relationships coupled with behaviors of anger, poor impulse control, and lack of remorse. Lynam (1996) indicates that children with RAD exhibit a lack of compassion for other people. 
Many children with attachment problems exhibit symptoms that are closely related to ODD and CD. Loeber, Lahey, and Thomas (1991) indicate that ODD and CD clients had a higher rate of parental rejection and out of home placements. They found associations between symptoms of ODD and coercive parenting techniques, while associations with CD were stronger for parent neglect. Schreiber and Lyddon (1998) present evidence that perceived higher parental bonding with either primary caregiver for victims of childhood sexual abuse was related to better psychological functioning. These findings would indicate that theory of attachment is linked to psychological functioning for victims of sexual abuse and that this population is at higher risk for problems of attachment. Schwartz and Davis (2006) indicate that children diagnosed with Reactive Attachment Disorder (RAD) demonstrated a decreased ability to self regulate, which directly affects their ability to function in an academic environment.

While attachment focuses on early childhood problems, research is beginning to connect attachment problems with the development of psychopathology in adolescents. Rosenstein and Horowitz (1996) studied the relationship between adolescent attachment. patterns defined by the Adult Attachment Interview, psychopathology, and personality in 60 psychiatrically hospitalized adolescents. They determined strong evidence that relational patterns with parents were correlated with psychopathology. Adolescents with attachment patterns classified as "dismissive" were diagnosed as having conduct or substance abuse disorders and self-reported traits of narcissistic, antisocial, and paranoid personality disorders. "Preoccupied attachment patterns" in adolescents were more often diagnosed with affective disorders and obsessive compulsive disorder, along with histrionic, borderline, and schizotypal personality disorders. Carlson (1998) conducted a 
longitudinal study of 157 children from 24 months to 19 years to determine the antecedents and consequences of disorganized attachment as defined by Main and Soloman (1986). Quality of attachment was measured using Ainsworth's Strange Situation procedure (Ainsworth et al., 1978). Behaviors were measured using the teacher report form of the CBCL. Psychopathology was measured using the Kiddie Schedule for affective disorders and Schizophrenia (K-SADS). It was determined that single parenting and maternal risk for parenting difficulties were correlated with disorganized attachment. Attachment disorganization was correlated with scores on the dissociative scales on the Teacher Report Form (TRF) of the Child Behavior Checklist (CBCL) for both middle school and high school age children. Children classified as having a disorganized attachment pattern were found to continue a pattern of poor quality of mother-child relationships, behavior problems in elementary school and high school, and ratings of psychopathology when tested at seventeen and a half years. Results indicated that successful predictors of adolescent psychopathology included clinically relevant avoidant attachment scores, attachment disorganization ratings, teacher rated behaviors in elementary school, and the quality of the parent-child relationship at age 13 as indicated by the K-SADS, the Strange Situation observations, and the scores on the CBCL. Predictors of adolescent dissociation include clinically relevant attachment disorganization ratings and teacher rated behavior scores in elementary school. Greenburg, Speltz, and DeKlyen (1993), in an extensive review of risk for disruptive behavior problems, reviewed the literature that supports a "multifactorial risk model" to include biological contributions, neuropsychological factors, temperament, family ecology, management styles and social practices of the parents, and early child-parent 
attachment relations. Insecure attachment in the first two years of life was related to lower social ability, increases in anger, poorer peer relations, and poor behavioral selfcontrol during the preschool years. (Greenburg et. al, 1988)

\section{Literature in Treating Attachment Disorders}

Many clinicians have developed therapies to treat children with attachment disorders and their families. The following paragraphs will review literature related previous therapies designed for this population.

\section{Holding therapy.}

Attachment Therapy or Holding Therapy (O'Connor \& Zeanah, 2003) consisted of treatment methods that are considered coercive, described by some as torturous, and can be retraumatizing to a child that has suffered abuse. While not all attachment therapies continue to use these coercive techniques, it is believed that they are still being practiced (Hanson \& Spratt, 2000). The methods employed by these therapists are still considered controversial and not recommended by the APSAC task force. (Chaffin et. al, 2006)

Hanson and Spratt (2000) indicated concern that coercive therapies will continue to be implemented due to a lack of alternative therapies that focus on the parent-child relationship rather than the psychopathology of the child. Holding therapy is not based in attachment theory and has not been supported by research (O'Connor \& Zeanah, 2003). Hanson and Spratt (2000) describes holding, attachment, or rage reduction therapy as coercive techniques and fear parents will engage in this coercive therapy as a last resort. Prolonged restraint not used to protect a child but to establish control and create 
submissive behaviors, prolonged unpleasant behavior such as tickling, poking, and interference with feeding and bodily functions are some of the techniques implemented in holding therapies.

\section{Dyadic developmental psychotherapy.}

Attachment theory posits that as children seek attachment and parents do not provide for the needs of the infant, and believe that rage develops in the absence of trust. It is a basic tenet of attachment therapy work that a child must regress to a developmental age when attachments did not form and work through those before positive attachments can form.

Dyadic Developmental Therapy for children with Reactive Attachment Disorder as described by Becker-Weidman (2006) has three components. The first is designed to help parents understand children with attachment disorder: how they feel, how they think, and their internal psychological dynamics. The teaching of attuned and responsive parenting skills comprises the second part. These skills are designed to help the parents engage the child emotionally in a growth enhancing relationship. The third component involves intensive emotional work with the child. This sometimes involves acting with the child in a fashion appropriate for dealing with an infant or toddler and engages the child in a role-play which includes confrontation of the abuser. Arthur Becker-Weidman found empirical support for dyadic developmental psychotherapy with a treatment group of 34 children using the CBCL and the RAD-Q. The definition of attachment is most closely related to attachment therapies and includes behaviors associated with the RAD$Q$ and all children in this study experienced trauma, which appears to be extreme pathogenic care. Research results indicated significant changes on scores using the RAD- 
Q and changes on CBCL syndrome scales of withdrawn, social problems, thought problems, attention problems, rule-breaking behavior, and aggressive behavior. While this study provides empirical support for dyadic developmental psychotherapy (Hughes, 1998), it does not appear to be applicable to community mental health settings, working with reunified families, or third party providers. The dyadic developmental psychotherapy studied by Becker-Weidman includes psychodramatic interventions that are geared toward working with foster and adoptive parents, which focus on a difference between the pathogenic care received previously and the care, which is implemented with a new family. This therapy is implemented in two-hour individual session and uses two offices. The typical community mental health facility working with managed care is not organized in a manner to accommodate these facilities or blocks of time this large.

\section{Theraplay.}

In "Short-term play therapy for children", Kaduson, Heidi, and Schaefer (2000), describe how Theraplay can be used effectively with children with AD. Theraplay involves parents in attachment-based play to strengthen the attachments between parents and their child. Theraplay has been found effective with children of domestic violence (Dodd, 2004), with children who have pervasive developmental disorders (Franklin, et. al, 2006, Park, 1999), and with children of abuse (Hong, 2004). While there is some evidence that Theraplay works, it incorporates the parents less in therapeutic interventions, does not appear to be as structured as CPRT, and research on Theraplay is not as extensive. 


\section{Parent child interaction therapy.}

Parent Child Interaction Therapy (PCIT) is another form of therapy that incorporates the parent in the therapeutic intervention in an effort to improve the attachment relationship between the parent and child. PCIT has been found effective in treating children with behavior disorders such as ODD and CD (Chase \& Eyberg, 2008; Banger \& Eyberg, 2007; Brinkmeyer, 2007), for children who suffered physical abuse (Herschell \& McNeil, 2005), and for maltreated children in foster care (Timmer et. al, 2006). Thomas and Zimmer-Gembeck (2008) found large effect sizes in a meta-analysis of PCIT for parent and child behaviors. Theoretically, it appears that PCIT could be used appropriately with children with AD. PCIT was not chosen for the current study because it relies heavily on a behavioral foundation and is typically used in individual sessions.

\section{Efficacy of Play Therapy}

LeBlanc and Ritchie (2001) provide results of a meta-analysis of 42 controlled studies focusing exclusively on play therapy. They reported an average effect size of 0.66 standard deviations. "Effect sizes were computed as $d=X_{e}-X_{c} / S_{p}$ with $X_{e}$ indicating mean scores of experimental group, $X_{c}$ indicating mean scores of control group, and $S_{p}$ indicating pooled standard deviations of the samples," and authors indicated statistical corrections for small sample sizes. They also reported that parental involvement was a significant predictor of statistically significant outcomes, with an effect size increase of 0.33 standard deviations. The researchers also investigated the effects of duration of therapy on outcomes, reporting that the average effect size (0.66) corresponded with approximately 13 play therapy sessions. Additional analysis was provided to determine if study characteristics could cause variations in effect sizes. No characteristics were 
found to cause variations including age of client, sex of client, individual or group format, or presenting problem. The studies presented in this meta-analysis did not investigate long-term effects of play therapy

Bratton, Ray, Rhine, and Jones (2004) provided results from a meta-analysis reviewing 93 treatment-control comparisons including 43 published studies and 50 unpublished dissertations. The authors calculated one effect size (d) per study and weighted each effect size by sample size. The meta-analysis found the average effect size was $0.80 \pm 0.04$ standard deviations for children receiving play therapy. Overall, the strongest benefits were found at 35 sessions. However, a larger effect size of 1.15 was found for parent-only filial therapy studies. Fourteen parent-only studies followed Landreth's (1991) 10-week filial therapy model and an additional 7 parent-only studies reported 8-13 sessions. Researchers suggest that play therapy models incorporating parent training, specifically filial parent training, may decrease the duration of treatment needed for optimal treatment effects.

\section{Efficacy of filial therapy.}

Filial therapy was first introduced in the 1960's by Bernard and Louise Guerneys (Guerney, 2000) as a structured method of training parents in child-centered play therapy. to allow them to become the therapeutic agent in their child's life. The 10-session model design by Gary Landreth and Sue Bratton (2005), chosen for the proposed study implementing filial therapy with children with attachment disorder, has proven successful in many different populations. Rennie and Landreth (2000) reviewed an extensive literature base to determine the effects of filial therapy on parent and child behaviors and found it to be a "powerful intervention for increasing parental acceptance, self-esteem, 
empathy, positive changes in family environment, and the child's adjustment and selfesteem while decreasing parental stress and the child's behavioral problems." Studies for Landreth's 10 session model reviewed further in chapter 2 include significant changes in empathy, acceptance, and parent stress for Chinese parents (Chau \& Landreth, 1997; Yuen, Landreth, and Baggerly, 2002), for Korean Parents in the United States (Lee \& Landreth, 2003), and changes in empathy and parental acceptance were found for Native American parents on the Flathead Reservation (Glover \& Landreth, 2000). Villarreal (2008) found changes in internalizing behaviors for English speaking Hispanic parents. This intervention was also successful for deaf and hard of hearing students (Smith \& Landreth, 2004) and children with learning difficulties (Kale \& Landreth, 1999).

Yuen, Landreth, and Baggerly, (2002) studied the effectiveness of filial therapy as a preventative measure for immigrant Chinese families in Canada. Analysis of covariance was used to determine if a significant difference between groups was found for empathy in parent-child interactions with the Parental Stress Index, parental acceptance and stress with the Porter Parental Acceptance Scale, child problem behaviors using the Filial Problem Checklist, and child self-concept with the Pictorial Scale of Perceived Social Competence and Social Acceptance of Young Children. Results of the study indicate statistical significance on all measures, indicating the generalization to an immigrant Chinese population.

Smith and Landreth (2004) use an adaptation of Landreth's 10-session filial therapy model used with teachers of deaf and hard of hearing students which was found to be effective. Analysis of Covariance was used to determine statistical significance for preschool students $(\mathrm{n}=12)$ compared to a control group $(\mathrm{n}=12)$. Statistical significance of 
difference between the means at the .05 level was found on the subscales for Total Behavior Problems, Internalizing Behavior, and Withdrawn Behaviors. No significance was found on the subscales for Eternalizing Behavior, Anxious/Depressed, and Aggressive Behavior. No significance was indicated for scales on the Medow-Kendall Social-Emotional Assessment Inventory of Deaf and Hearing Impaired students (SEAI). Villarreal (2008) found changes in internalizing behaviors of children with the Behavior Assessment Scale for Children (BASC-2, Reynolds \& Kamphaus, 2004) incorporating CPRT for English speaking Hispanic parents. Final data was collected on 14 parents in a study using a quasi-experimental pre-test post-test design and t-test comparisons for analysis. According to parent reports, statistically significant decreases in internalizing child behaviors were found. Positive trend toward statistical significant decreases in externalizing behaviors were also found on the Parent Rating Scale. Teacher rating scales did not produce statistically significant changes. Garza (2005) studied child centered play therapy with Hispanic children in the school setting but did not use a model incorporating parents in play sessions. The researcher found positive decreases in externalizing behaviors with the Behavior Assessment Scales for Children, Parent Rating Scale. Ceballos and Bratton (2010) found significant decreases in child behavior problems for 48 children of Latino immigrants using CPRT referred in the school setting. Kale and Landreth (1999) found changes in parental acceptance and parental stress, but no significant difference in behavior for children with learning difficulties. Final data was collected on 11 parents in the experimental group following attrition of 8 parents while the control group consisted of 22 parents. Analysis of Covariance was calculated to determine the significance of adjusted posttest means. Significance was 
found for most measures on the Porter Parental Acceptance Scale with the exception of no difference between experimental and control groups on the measure of "unconditional love". No differences were found on Total Behavior, Externalizing Behavior, and Internalizing Behavior on the teacher or parent scales for the Child Behavior Checklist. Researchers report that behavior changes may not be exhibited due to the time frame established for the CBCL. Limitations, many children participating in the study had not been formally diagnosed with learning disabilities and parents were recruited using flyers.

While the overall success of filial therapy models indicates this intervention is one of the best methods for children in general, many studies investigating populations considered at high risk for attachment disorders indicates a strong likelihood that this intervention would be successful in treating children who exhibit signs of attachment disorder. Filial therapy was determined effective for mothers of children with chronic illness (Glazer-Waldman, et al., 1992, Tew, Landreth, Joiner, \& Solt, 2002), parents of children who have witnessed domestic violence (Smith \& Landreth, 2003) non-offending parents of children who were sexually abused (Costa and Landreth,1999), incarcerated mothers (Harris \& Landreth, (1997), parents of children diagnosed as emotionally maladjusted (Stover \& Guerney, 1967). Bratton and Landreth (1995) reported significant increases in empathy and acceptance, significant decreases in stress related to parenting, and decreases in behavior problems for children ages 3-7.

Mothers of five Children with Chronic Illness (Glazer-Waldman, et al., 1992) reported more accurately assessing their child's level of stress and positive changes in their relationship with their children. Tew, Landreth, Joiner, \& Solt (2002) also investigated CPRT with parents of chronically ill children to include a control group and 
a slightly larger sample size, $\mathrm{N}=12$. They reported significant changes including a decrease in parenting stress, an increase in parental acceptance, and a decrease in the number of behavior problems their children exhibited.

Filial Therapy with child witness of Domestic Violence (Smith \& Landreth, 2003) was studied with a group of 11 children. Comparison groups used did not receive treatment. Outcomes for this study were based on scores on the Child Behavior Checklist (CBCL), the Joseph Pre-school and primary self-concept screening test (JSCS), and the Measurement for Empathy in Adult-Child Interaction (MEACI). Significant change in behavior and self-concept were found for all filial therapy groups when compared to the no treatment group. Significant changes in Empathy reported by the mother were found for the filial therapy group.

Costa and Landreth (1999) found positive trends in behavior changes and child self-concept, significant increases in parental acceptance and empathy, and significant decreases in child anxiety were found for children who were sexually abused and who received filial therapy. The filial therapy was provided for the non-offending parents of children who have been sexually abused. A group of 31 children were included in the study and researchers employed a waitlist control group. Measures used to determine behavior and self-concept changes included Porter Parental Acceptance Scale (PPAS), Parenting Stress Index (PSI), Child Anxiety Scale (CSA), CBCL, and JCSC. Harris \& Landreth, (1997) studied Filial Therapy with Incarcerated Mothers with 51 children using a control group with no treatment. Significance found for an increase in empathy and parental acceptance scales on the PPAS, and significant reduction in behavior problems 
was found using the Filial Problem Checklist. Using the PSI, researchers found no significant decrease in parent stress on the PSI.

Stover and Guerney (1967) found efficacy of filial therapy techniques on children diagnosed as emotionally maladjusted. The researchers compared behaviors of children and their mothers in experimental groups receiving training in filial therapy ( $\mathrm{n}=14)$ with a wait-list control group $(\mathrm{N}=14)$. All dependent measures used were structured observations of videotapes. They used a coding procedure developed in part by the author of this study. Interrater reliability statistics ranged from .67 to .99 for mother's behaviors of reflective and directive verbal behavior and .66 to .93 on child behaviors of active aggression, verbal negative feelings, verbal dependency, and verbal leadership.

Percentage of reflective statements increased significantly for experimental groups while control groups saw no change. The experimental group one had a mean gain of 15 percent and groups two having a mean gain of 58 percent. In regards to child behaviors, active aggression and verbal negative feeling showed statistically significant changes when compared to the control groups, while verbal dependency and verbal leadership were not statistically different.

Bavin-Hoffman, Jennings, and Landreth (1996) investigated perceptions that parents have of the filial therapy process one year after a 10-week model of Landreth's filial therapy. This qualitative research revealed that parents perceived improvements in the child-parent relationship, in child behavior, and improved communication between spouses. More than $3 / 4$ of parents (mothers and fathers) indicated improvement in child behaviors, specifically reporting improvements in self-control and aggression. Only 2 participants reported that behavior had worsened since discontinuing play therapy 
sessions. Sixteen of twenty mothers and 14 of 20 fathers reported improved communication with their spouse, which was not a specific intention of the therapeutic process. A limitation of the study is that it includes no comparison groups to determine if other therapies would be as effective.

\section{Purpose/Significance}

While there is controversy regarding the diagnosis of attachment disorders and the need for stronger criteria is valid, it is important to begin critical analysis of the treatments being recommended for children with attachment disorder. Many researchers indicate that the need for better diagnostic criteria exist prior to conducting this critical research (Chaffin et. al, 2006; Hanson \& Spratt, 2000; O’Connor \& Zeanah, 2003), however clinicians are currently diagnosing attachment disorders and treating the attachment and comorbid behavior disorders with therapeutic interventions designed for other disorders and are using interventions recommended for attachment disorders which have not been empirically validated (Chaffin et. al, 2006; Hanson \& Spratt, 2000;

O'Connor \& Zeanah, 2003). Techniques used by some clinicians have been proven to be coercive in nature and are not recommended; however, many parents with children who have attachment disorders become frustrated with current treatment options that do not appear to work and may turn to alternative coercive therapies thinking they have no other options. This study sets out to empirically validate CPRT for children with attachment problems. 


\section{Basis for Hypothesis}

Given theoretical models discussed, interventions should target attachment to primary caregiver, improve therapeutic manner of setting boundaries, focus on relationship between parent and child, increase parental empathy, and reduce parent stress. Cornell and Harmin (2008) reviewed literature in therapeutic interventions for children with attachment problems and concluded that interventions that included both a psycheducational and psychotherapeutic element would be necessary to facilitate the child-parent attachment relationship in treatment. Haugaard \& Hazan (2004) recommend goals of intervention for children with reactive attachment disorder to include the caregiver to provide, "(a) a source of emotional security, (b) opportunities for corrective social experiences, and (c) better social skills" (p.156). O'Connor and Zeanah (2003) suggest including an educational component and networking opportunities for parents regarding attachment disorder to help address caregiver feelings of frustration, distress, isolation, and incompetence. Lyons (2007) recommends the involvement of caregivers in treatment, focus on enhancing current attachment patterns, and creating new attachment relationships. Ginsberg, (1976, 2002) recommends 'Filial Relationship Enhancement', described as training parents to provide child-centered therapy session in the home as an intervention for victims of child abuse and neglect. Ginsberg reviews the rationale for the recommendation of filial therapy to include an emphasis on learning constructive methods for engaging children, it teaches parents to view their children in a more developmentally appropriate manner, focuses on familial strengths, and improves selfacceptance and emotional regulation. Ginsberg describes outcomes of a filial therapy program in Bucks County, Pennsylvania, Children and Youth Social Services Agency 
that was presented by Cosner at the 1990 American Psychological Association Conference. Of 70 client families seen during the three year study, more than $50 \%$ of the parents reported increased positive contact with their child, one-third felt more confident and less frustrated when working with the child, and one quarter reported that their child was more cooperative during play. Child Parent Relationship Therapy (CPRT), a 10session model of filial therapy designed by Landreth and Bratton, is an excellent match for the guidelines from the APA, recommendations from attachment literature, and is congruent with attachment theory. Research related to improvements in the caregivers relationship with their child, the match with attachment literature, and congruence with guidelines from APA contributed to the development of research hypotheses for the current study.

\section{Research Questions}

The purpose of the proposed study is to determine the effectiveness of filial therapy in (a) decreasing behavior problems exhibited by the child, (b) decrease the symptoms associated with attachment disorder, and (c) increase the quality of family life. The study addresses the following research questions:

1. Will caregivers that participated in the CPRT group report their children with attachment problems exhibit fewer post-treatment externalizing problems compared to the control group?

2. Will teachers of children with attachment problems whose caregivers participated in the CPRT group report fewer post-treatment externalizing problems compared to the control group? 
3. Will caregivers that participated in the CPRT group report their children with attachment problems exhibit fewer post-treatment internalizing problems compared to the control group?

4. Will teachers of children with attachment problems whose caregivers participated in the CPRT group report fewer post-treatment internalizing problems compared to the control group?

5. Will caregivers that participated in the CPRT group report their children with attachment problems exhibit fewer symptoms of attachment compared to the control group?

6. Will caregivers who participated in the CPRT group report an improvement of their perceived quality of family life compared to the control group? 


\section{CHAPTER III}

\section{METHODS}

The purpose of this dissertation was to determine if Child Parent Relationship Therapy (CPRT, Landreth \& Bratton, 2006), a 10-session model of Filial therapy (FT) is an effective treatment for caregivers of children with attachment problems. The study focused on changes following caregiver participation in CPRT groups in (a) internalizing problems of children (i.e., those behaviors that are directed inward, such as anxiety, depression, and somatic complaints), (b) externalizing problems of the child (i.e., those behaviors that are directed outward, such as, aggression, hyperactivity, and conduct problems) (c) changes in number of attachment disorder symptoms present, and (d) changes in the family social environment as perceived by the caregiver. The research design was a quasi-experimental design with a pre-test/post-test waitlist control group.

This chapter reviews hypotheses, recruitment of subjects, sample, subject assignment, design of study, treatment implementation, training for therapist, measures for analysis, and data analysis.

\section{Research Hypotheses}

1. The children with attachment problems whose caregivers participated in the CPRT group will exhibit fewer post-treatment externalizing problems compared to the control group, controlling for pre-treatment differences in externalizing problems reported by caregivers. 
2. The children with attachment problems whose caregivers participated in the CPRT group will exhibit fewer post-treatment externalizing problems compared to the control group, controlling for pre-treatment differences in externalizing problems reported by teachers.

3. The children with attachment problems whose caregivers participated in the CPRT group will exhibit fewer post-treatment internalizing problems compared to the control group, controlling for pre-treatment differences in internalizing problems reported by caregivers.

4. The children with attachment problems whose caregivers participated in the CPRT group will exhibit fewer post-treatment internalizing problems compared to the control group, controlling for pre-treatment differences in internalizing problems reported by teachers.

5. The children with attachment problems whose caregivers participated in the CPRT group will exhibit fewer symptoms of attachment compared to the control group, controlling for pre-treatment differences in symptoms of attachment.

6. The caregivers who participated in the CPRT group will report an improvement of their perceived family social environment compared to the control group, controlling for pre-treatment differences in perception of family social environment. 


\section{Population and Sample}

The population to which this study is attempting to generalize is caregivers of children with attachment problems receiving treatment in an urban community mental health center $(\mathrm{CMHC})$. The intended population was a diverse sample from several sites within this $\mathrm{CMHC}$ that serves Louisville, $\mathrm{KY}$ and the surrounding six counties.

The specific sample was drawn in the following manner. The research was conducted in an urban (CMHC) setting serving Louisville, KY and the surrounding six counties. However, subjects all received services in one outpatient site. The site serves approximately 1600 children and adults to include behavioral health, developmental services, and trauma services. I applied for approval to use human subjects from the Institutional Review Board (IRB) from the University of Louisville (UL). After approval from UL, I received permission from Seven Counties Services, Inc. (SCS) IRB and the Jefferson County Public Schools (JCPS) IRB.

Subjects were children and their caregivers referred by the child's primary therapist at SCS. Subjects referred included children between the ages six and ten receiving services in a CMHC setting. Children and their caregivers were referred for participation if the child exhibited three or more symptoms and characteristics of attachment disorder based on literature by Boris and Zeanah (2005). A checklist for inclusion was created for this study (see Appendix A) to include symptoms and characteristics of attachment disorder. Therapists completed the checklists based on observations and a history of reports by caregivers and other helping professionals. Caregivers included custodial grandparents, custodial aunts, foster parents, adoptive parents, and parents. 
For the purposes of this study, attachment disorder was defined as a failure to form normal attachments with a primary caregiver in early childhood resulting in disorders of mood, behavior, and/or social relatedness. Symptoms and characteristics included a history of removal from the primary caregiver or significant disruption in the child's relationship with the primary caregiver, significant lack of affection with primary caregiver, indiscriminate friendliness across a range of interactions, lack of comfort seeking or comfort seeking in an ambivalent manner, an excessive dependence on caregiver determined to be developmentally inappropriate, inability to seek support when needed as developmentally appropriate, pervasive lack of compliance with caregiver or fearful compliance with caregiver, failure to check back with caregiver or complete unwillingness to leave caregiver, lack of affection or avoidance or failure to resolve distress following separation, willingness to go with stranger without protest or seeking reference from caregiver, and immediate engagement with or excessive physical contact with strangers without seeking reference from caregiver. I contacted caregivers referred for service to arrange a meeting or phone call to provide information about the CPRT group treatment and review all components of the informed consent, research authorization, and subject assent. Signatures were acquired on all relevant for documentation reviewed above and caregivers completed an initial data packet that included a demographic questionnaire (see Appendix B), the Parent Rating Scale (PRS) of the Behavior Assessment System for Children, $2^{\text {nd }}$ Ed. (BASC-2, Renoylds \& Kamphaus, 2000), the Family Environment Scale (FES: Moos \& Moos, 1994), and the Randolph Attachment Disorder Questionnaire (RAD-Q). I contacted teachers of the subjects' children by phone, mail, and email to request participation and reviewed the 
teacher informed consent and the Teacher Rating Scale (TRS) of the Behavior Assessment System for Children (BASC-2, Reynolds \& Kamphaus, 2004). If teachers agreed to participate, signatures were acquired for informed consent and they completed the initial TRS.

Sixty-two children were referred for CPRT group based on the criteria above and thirty four caregivers of those children agreed to participate in this research study. The sample for this study was subjects predominately residing in Louisville, KY with one subject residing in a surrounding county. All subjects received services in one outpatient site. Teachers of seventeen children agreed to participate. One subject was excluded from analysis because the caregiver reported that she participated in CPRT treatment with the child's therapist while on the waitlist.

\section{Sample characteristics.}

Characteristics of the subjects included in analysis are reviewed in Tables 1 and 2. Demographics to include number of family members in the home and employment, income, and education of caregiver are described in Table 1. Symptoms and characteristics of attachment identified by the child's primary therapist are described in Table 2.

\section{Demographic information of sample.}

Review of demographic information between groups indicates that subjects who dropped out of the study had 2 or more children living in the home (100\%) compare to the treatment group (57.1\%) or the control group (64.7\%). Data indicates a higher number of subjects with Medicaid coverage in the drop out group (77.8\%) and the control group $(70.6 \%)$ when compared to the treatment group (42.9\%). Demographic data 
indicates the number of subjects that have more than a high school education is lower in the drop out group (10\%) when compared to the treatment group (80\%) and the control group (41.2\%).

Table 1

Sample Demographic Characteristics

\begin{tabular}{cccc}
\hline Group & Dropouts & Treatment & Control \\
$\mathrm{n}=10$ & $\mathrm{n}=15$ & $\mathrm{n}=17$ \\
\hline
\end{tabular}

\begin{tabular}{|c|c|c|c|}
\hline \multirow[b]{2}{*}{1} & \multicolumn{3}{|c|}{ Numbers of Adults in the Home } \\
\hline & 5 & 7 & 8 \\
\hline 2 & 2 & 6 & 8 \\
\hline \multirow[t]{2}{*}{3} & 2 & 1 & 1 \\
\hline & \multicolumn{3}{|c|}{ Number of Children in the Home } \\
\hline 1 & 0 & 6 & 6 \\
\hline 2 & 4 & 5 & 4 \\
\hline 3 & 4 & 1 & 3 \\
\hline \multirow[t]{2}{*}{4} & 1 & 2 & 4 \\
\hline & \multicolumn{3}{|c|}{ Employment } \\
\hline
\end{tabular}

Not Working Outside of Home Working $\begin{array}{lll}4 & 5 & 8 \\ 3 & 7 & 8\end{array}$

Yearly Household Income

15019 or below $15020-24259$ 24260-30419 30420 or higher

Yes

No

$\longrightarrow$

\begin{tabular}{lll}
\hline & & \\
3 & 8 & 10 \\
4 & 1 & 3 \\
0 & 3 & 0 \\
2 & 2 & 4
\end{tabular}

Medicaid Coverage

\begin{tabular}{ccc}
\multicolumn{3}{c}{ Medicaid Coverage } \\
\hline 6 & 3 & 0 \\
6 & 6 & 7
\end{tabular}


Table 1 con't.

Sample Demographic Characteristics

\begin{tabular}{lccc}
\hline Group & $\begin{array}{c}\text { Dropouts } \\
\mathrm{n}=10\end{array}$ & $\begin{array}{c}\text { Treatment } \\
\mathrm{n}=15\end{array}$ & $\begin{array}{c}\text { Control } \\
\mathrm{n}=17\end{array}$ \\
\cline { 2 - 4 } & \multicolumn{3}{c}{ Caregiver's Highest Level of Education } \\
\cline { 2 - 4 } & 1 & 1 & 2 \\
$8^{\text {th }}$ Grade or Less & 8 & 2 & 8 \\
High School Graduate & 0 & 6 & 4 \\
Some College or Tech & 1 & 6 & 3 \\
2- or 4-year College Degree & & & \\
\hline
\end{tabular}

\section{Symptoms and characteristics of attachment for sample.}

Review of symptoms and characteristics of attachment between groups indicates that subjects were similar for most symptoms and characteristics of attachment. Therapists identified fewer subjects with indiscriminate friendliness across a range of interactions in the dropout group (10\%) when compared to the treatment group $(33.3 \%)$ and the control group (29.4\%). Subjects identified as having a pervasive lack of compliance with the primary caregiver or fearful compliance with the primary caregiver was higher in the treatment group (80\%) when compared to the control group $(58.8 \%)$ and the dropout group (50\%). Differences between groups occurred by chance.

Table 2

Sample Characteristics of Attachment

\begin{tabular}{lccc}
\hline Group & $\begin{array}{c}\text { Dropout } \\
\mathrm{n}=10\end{array}$ & $\begin{array}{c}\text { Treatment } \\
\mathrm{n}=15\end{array}$ & $\begin{array}{c}\text { Control } \\
\mathrm{n}=17\end{array}$ \\
\hline $\begin{array}{l}\text { History of removal from the primary caregiver } \\
\text { (PC) }\end{array}$ & 4 & 7 & 11
\end{tabular}


Table 2 cont.

Sample Characteristics of Attachment

\begin{tabular}{|c|c|c|c|}
\hline Group & $\begin{array}{c}\text { Dropout } \\
\mathrm{n}=10\end{array}$ & $\begin{array}{c}\text { Treatment } \\
\mathbf{n}=15\end{array}$ & $\begin{array}{c}\text { Control } \\
\mathrm{n}=17\end{array}$ \\
\hline Significant disruption in relationship with PC & 7 & 7 & 12 \\
\hline Significant lack of affection with PC & 5 & 8 & 9 \\
\hline $\begin{array}{l}\text { Indiscriminate friendliness across range of } \\
\text { interactions }\end{array}$ & 1 & 5 & 5 \\
\hline $\begin{array}{l}\text { Lack of comfort seeking or ambivalent } \\
\text { interactions }\end{array}$ & 8 & 10 & 12 \\
\hline Excessive dependence on PC & 4 & 4 & 9 \\
\hline Inability to seek support when needed & 2 & 9 & 7 \\
\hline $\begin{array}{l}\text { Pervasive lack of compliance or fearful } \\
\text { compliance with PC }\end{array}$ & 5 & 12 & 10 \\
\hline $\begin{array}{l}\text { Failure to check back with PC or unwillingness } \\
\text { to leave PC }\end{array}$ & 1 & 4 & 5 \\
\hline $\begin{array}{l}\text { Lack of affection or failure to resolve } \\
\text { separation distress }\end{array}$ & 4 & 3 & 6 \\
\hline $\begin{array}{l}\text { Willingness to go with strangers, no reference } \\
\text { seeking with PC }\end{array}$ & 1 & 3 & 2 \\
\hline $\begin{array}{l}\text { Immediate engagement or excessive physical } \\
\text { contact with strangers, no reference seeking } \\
\text { with PC }\end{array}$ & 1 & 1 & 2 \\
\hline
\end{tabular}




\section{Subject Assignment}

In the initial stages of the study, subjects were randomly assigned to a treatment group receiving CPRT or to a waitlist control group receiving standard services. A control waitlist design was implemented because it is unethical to deny clients access to services. Due to small group sizes, trickle process randomization was used to assign subjects during the last stage of the study. Changes in groups were adjusted due to needs of the agency and clients. Subjects were referred in such low numbers that after random assignment and subjects dropping out of treatment, there were not enough group members for Seven Counties, Inc. to justify conducting group. Changes in agency administration also caused complications leading to low referral rates. All subjects assigned to a waitlist control group had access to all other services offered by the CMHC followed by the opportunity for CPRT group services. Table 3 provides an overview of subject assignment and subject drop out. Twelve subjects were assigned to treatment only with two dropping out before completing post-test data. Ten subjects were assigned to the waitlist control group with one subject dropping out before completing post-test control group data and four subjects dropping out before completing post-test treatment group data. Twelve subjects were assigned to the control group with four dropping out before completing post-test data. 
Table 3

Subject Analysis

\begin{tabular}{lcccc}
\hline \multirow{2}{*}{ Group } & Assignment & \multicolumn{2}{c}{ Completed Data } & Drop Out \\
\cline { 3 - 4 } Treatment & 12 & 10 & Control & \\
Control & 12 & 0 & 8 & 4 \\
Control to Treatment & 10 & 6 & 9 & 4 \\
\hline
\end{tabular}

\section{Design}

This study utilized a quasi-experimental pre-test post-test waitlist control group design with random assignment (see Table 4). Trickle process randomization was utilized during the last stage of the study to have a treatment group large enough to provide services. The same measures, BASC-2, RAD-Q, and FES described below, were implemented prior to treatment and control waitlist, at the end of the ten week treatment, and ten weeks after treatment.

Table 4

Research Design

\begin{tabular}{llllll}
\hline Wave 1 Treatment & $\mathrm{R}$ & $\mathrm{O}_{1}$ & $\mathrm{X}$ & $\mathrm{O}_{2}$ & $\mathrm{O}_{3}$
\end{tabular}

$\begin{array}{lllllll}\text { Wave } 1 \text { Control } & \mathrm{R} & \mathrm{O}_{1} & \mathrm{O}_{2} & \mathrm{X} & \mathrm{O}_{3} & \mathrm{O}_{4}\end{array}$

$\begin{array}{llllll}\text { Wave 2 Treatment } & \mathrm{R} & \mathrm{O}_{1} & \mathrm{X} & \mathrm{O}_{2} & \mathrm{O}_{3}\end{array}$

$\begin{array}{llllll}\text { Wave 2 Control } & \mathrm{R} & \mathrm{O}_{1} & \mathrm{O}_{2} & \mathrm{X} & \mathrm{O}_{3}\end{array}$

Wave 3 Control

$\mathrm{R}$

$\mathrm{O}_{1}$

$\mathrm{O}_{2}$ 
The subjects assigned during the first and second waves of the study were placed in a treatment group or on a waitlist control group who served as the treatment group in the following wave of services. Subjects assigned during the third wave of the study all served as waitlist control subjects. The control group had access to all services normally received in the CMHC setting by therapists trained at the Bachelors, Masters, or Doctoral level in the field of counseling and/or social work but did not receive specialized treatment in filial therapy. The design controlled for the threat to internal validity of selection bias. Random assignment was implemented to control for selection bias. However, the sample size was relatively small and selection bias would still be a concern. The design was analyzed following the third wave of subject assignment; however, subjects were offered treatment following the completion of the study and the design would allow for continued measurement.

\section{Treatment}

CPRT developed by Drs. Landreth and Bratton (2005) is a ten-session filial therapy model used in the CMHC. Filial therapy's focus is to train caregivers to act as therapeutic agents with their own children using a structured system of didactic instruction, demonstration of play sessions by therapists, videotaped practice play sessions by caregivers, and supervision in a supportive atmosphere in a 2 -hr weekly group format. The initial training for caregivers provided education and practice in skills for conducting play sessions in the home. Skills included setting up a play session, how to allow children to guide play, how to identify their child's feelings, how to address feelings in a supportive manner, how to set boundaries in a supportive and therapeutic manner, and communication techniques that build relationships. After initial training, 
videotapes are reviewed in groups and feedback is provided to build on skills and more intensive training is implemented for skills mentioned above.

\section{Therapist Training}

Therapists received extensive training prior to implementation of CPRT groups. Training consisted of one eight hour session of child centered play therapy and 45 hours of CPRT training. Individualized training included education in client centered play therapy and CPRT, skills practice for client centered play therapy and CPRT, review of therapist video tapes and feedback provided by two licensed play therapists who received specialized training in the CPRT model with Drs. Landreth and Bratton. Each therapist providing leadership for the groups have received no less than two feedback sessions with a trained filial therapist.

\section{Measures}

Demographic information on age, gender, ethnicity, SES, current treatment, previous treatment and psychotropic medications were collected. A checklist for therapeutic interventions for children of subjects while serving in the waitlist control group and during treatment was completed to determine if alternative treatments accounted for differences between groups (see Appendix C). The total scores and internalizing and externalizing subscale scores of the Behavioral Assessment System for Children (BASC-2), Randolph Attachment Disorder Questionnaire (RAD-Q), and the Family Environment Scale (FES) were used to measure outcome variables.

\section{Additional therapeutic interventions of subjects.}

Information regarding additional therapies that subjects engaged in during the study was collected by therapists at Seven Counties Services, Inc. through the medical 
records system. Table 5 describes therapeutic services that subjects sought while in the waitlist control group and while engaging in CPRT groups. Subjects in the waitlist control group engaged in a higher percentage of individual therapy $(51.5 \%)$ compared to subjects in the treatment group (27.3\%). Engagement in other alternative therapies was similar between groups. A higher percentage of additional child therapies and parent collateral services would have been expected for the subjects waiting for treatment.

Table 5.

Additional Therapeutic Interventions of Subjects

\begin{tabular}{lcccc}
\hline Group & \multicolumn{2}{c}{$\begin{array}{c}\text { Treatment } \\
\mathrm{n}=33\end{array}$} & \multicolumn{2}{c}{$\begin{array}{c}\text { Waitlist Control } \\
\mathrm{n}=33\end{array}$} \\
\hline & Frequency & Percent & Frequency & Percent \\
\hline Individual Therapy & 9 & 27.3 & 17 & 51.5 \\
Child Group Therapy & 3 & 9.1 & 2 & 6.1 \\
Individual Parent Collateral & 8 & 24.2 & 9 & 27.3 \\
Parent Collateral Group & 4 & 12.1 & 2 & 6.1 \\
Family Therapy & 12 & 36.4 & 14 & 42.4 \\
In-home Therapy & 0 & 0 & 2 & 6.1 \\
School-based Therapy & 1 & 3.0 & 2 & 6.1 \\
\hline
\end{tabular}

\section{Behavioral assessment system for children.}

The Behavioral Assessment System for Children, $2^{\text {nd }}$ Edition (BASC-2, Reynolds \& Kamphaus, 2004) is used to aid in identification and differential diagnosis of emotional and behavior disorders in children and adolescents. The BASC -2 provides scores on 26 
scales covering a wide range of behavior and emotional difficulties. Scales include Externalizing Problems (Aggression, Hyperactivity, Conduct Problems), Internalizing Problems (Anxiety, Depression, Somatization), School Problems (Attention Problems, Learning Problems), Atypicality, Withdrawal, Adaptive Skills (Adaptability, Social Skills, Leadership, Study Skills), Clinical Maladjustment (Locus of Control, Social Stress), School Maladjustment (Attitude to School, Attitude to Teachers), Sensed Inadequacy, Personal Adjustment (Relations with Parents, Interpersonal Relations, Self-Esteem, SelfReliance), Behavioral Symptoms Index, Emotional Symptoms Index, and Sensation Seeking. This study used the Parent Rating Scales (PRS) and the Teacher Rating Scales (TRS). Both the TRS and PRS provide clinical scales, adaptive scales, and scales for Externalizing and Internalizing Problems. The TRS includes scales to assess School Problems (learning problems and study skills) not assessed with the PRS. The PRS assess Activities of Daily Living not assessed on the TRS. A clinical norm also indicated the BASC-2 is adequate in identifying behavior and emotional disorders. Concurrent validity correlations with the scales of the Child Behavior Checklist were between 0.71 and 0.84 . Coefficient Alpha for Externalizing Problems was 0.97 on the TRS and 0.95 for the PRS and 0.91 for Internalizing Problems for the TRS and 0.92 for the PRS. Test-Retest reliability for Externalizing Problems was 0.90 for the TRS and 0.91 for the PRS, and for Internalizing Problems were 0.84 for the TRS and 0.77 for the PRS. Inter-rater reliability for the TRS was 0.63 for Externalizing Problems and 0.45 for Internalizing Problems, indicating analysis of TRS scores should be interpreted with caution. In this study internal consistency for scores on Internalizing Problems was 0.75 on the TRS and 0.92 for the PRS and Externalizing Problem was 0.96 on the TRS and 0.89 on the PRS. 


\section{Randolph attachment disorder questionnaire.}

Number of attachment disorder symptoms was assessed using the Randolph Attachment Disorder Questionnaire (RAD-Q, Randolph, 1999). This measure was designed as a tool to obtain information regarding the symptoms reported by caregivers of children diagnosed with attachment disorders. The measure is not intended to be used alone as a diagnostic measure but will provide additional information about symptoms of attachment for subjects included in this study. The RAD-Q is a 30-item questionnaire developed from the Attachment Disorder Symptom Checklist. Test-retest reliability was reported by Randolph (1999) with correlation coefficients between 0.82 and 0.85 . Internal consistency was reported as a Kronbach's alpha between 0.84 and 0.81 . In this study internal consistency was 0.89 for the RAD-Q. Validity reported by Randolph in the RAD-Q treatment manual include predictive validity for pre to post-treatment change scores $(t=17.69, p<.001)$ for 45 subjects. The lack of independent research utilizing the instrument limits the validity of the instrument. The RAD-Q should not be used alone to diagnose attachment disorders and should be interpreted with caution in research due to the lack of validity support in the current literature. A total RAD-Q score was utilized for analysis in this study.

\section{Family environment scale.}

The Family Environment Scale (FES, Moos \& Moos, 1994) is designed to assess family members' perceptions of their social environment. Scores on the FES include Cohesion, Expressiveness, Conflict, Independence, Achievement Orientation, Intellectual-Cultural Orientation, Active-Recreational Orientation, Moral-Religious Emphasis, Organization, and Control. The FES has been extensively used in research to 
include populations such as conduct disorder, substance abuse, and families with sexual and physical abuse. (Moos \& Moos, 1994) Alpha coefficients for internal consistency across scales ranged from 0.61 for the Independence scale to 0.78 for the Cohesion scale. In this study internal consistency across scales ranged from 0.17 for the Achievement Orientation scale to 0.65 for the Conflict and Moral Religious Emphasis scales. Testretest reliability at 2 months ranged from 0.68 for Independence to 0.86 for cohesion. Mancini (Mental Measurement Yearbook, 2001) suggested that statistics indicate the FES is relatively stable for the Cohesion, Expressiveness, Independence, Intellectual and Conflict, and Recreational Orientation scales. Orientation and Organization showed the greatest stability. This study examined scores for each of the FES scales.

\section{Correlations between measures.}

Correlations between scales on the BASC-2, the RAD-Q, and scales on the FES are provided in Table 6 . There was a strong correlation between Internalizing Problems reported by caregivers and teachers $(0.482, \mathrm{p}<.01)$. Negative symptoms of attachment had a strong correlation with Externalizing problems reported by caregivers $(.594, \mathrm{p}<.01)$ and caregiver perception of cohesion in the family social environment $(-0.394, \mathrm{p}<.01)$. 
Table 6

Correlation Coefficients for Relations between Internalizing Behaviors, Externalizing Behaviors, Attachment Symptoms, and Family Social Environment

\begin{tabular}{|c|c|c|c|c|c|c|c|c|c|c|c|c|c|c|c|c|c|}
\hline Variable & $\mathrm{M}$ & SD & 1 & 2 & 3 & 4 & 5 & 6 & 7 & 8 & 9 & 10 & 11 & 12 & 13 & 14 & 15 \\
\hline \multicolumn{18}{|c|}{ Internalizing Behaviors } \\
\hline 1. INT Teacher & 52.6 & 9.50 & 1.0 & $.482^{* *}$ & $.425^{*}$ & .234 & .074 & -.128 & .125 & .056 & -.074 & -.113 & .017 & -.346 & .094 & .136 & $-.452 *$ \\
\hline $\begin{array}{l}\text { 2. INT } \\
\text { Parent/Caregiver }\end{array}$ & 62.2 & 14.68 & & 1.0 & .048 & $.385^{*}$ & .227 & -.276 & .097 & .070 & -.228 & .107 & .055 & -.259 & -.248 & .046 & .007 \\
\hline \multicolumn{18}{|c|}{ Externalizing Behaviors } \\
\hline 3. Ext Teacher & 58.8 & 12.57 & & & 1.0 & $.424^{*}$ & .181 & -.163 & .260 & -.077 & .195 & .124 & -.142 & .033 & .080 & -.274 & $-.549^{* *}$ \\
\hline $\begin{array}{l}\text { 4. Ext } \\
\text { Parent/Caregiver }\end{array}$ & 69.2 & 11.82 & & & & 1.0 & $.594^{* *}$ & .286 & .077 & .229 & -.044 & -.043 & -.185 & .081 & -.113 & -.262 & -.130 \\
\hline Attachment Symp & oms & & & & & & & & & & & & & & & & \\
\hline $\begin{array}{l}\text { 5. Attachment } \\
\text { Symptoms }\end{array}$ & 52.3 & 20.45 & & & & & 1.0 & $-.394^{* *}$ & -.008 & .191 & -.129 & -.190 & -.170 & -.048 & -.174 & -.239 & -.013 \\
\hline
\end{tabular}

\section{Familv}

Environment

\begin{tabular}{|c|c|c|c|c|c|c|c|c|c|c|c|c|}
\hline 6. FES C & 42.8 & 13.02 & 1.0 & .154 & $-.527^{* *}$ & $.481^{* *}$ & .015 & $.436^{* *}$ & $.382^{*}$ & .103 & $.337^{*}$ & $-.334^{*}$ \\
\hline 7. FES EX & 47.3 & 11.34 & & 1.0 & -.072 & .212 & -.005 & .120 & .019 & -.177 & .015 & $-.427^{* *}$ \\
\hline 8. FES CON & 57.5 & 13.08 & & & 1.0 & $-.507^{* *}$ & $-.340^{*}$ & $-.461^{* *}$ & $-.354^{*}$ & .006 & $-.501^{* *}$ & $.361^{*}$ \\
\hline 9. FES IND & 42.5 & 14.94 & & & & 1.0 & .234 & .128 & $.352^{*}$ & -.098 & .204 & $-.384^{*}$ \\
\hline 10. FES AO & 50.9 & 7.57 & & & & & 1.0 & .066 & .093 & .192 & .219 & .017 \\
\hline 11. FES ICO & 45.8 & 10.67 & & & & & & 1.0 & $.333^{*}$ & .245 & $.379^{*}$ & -.157 \\
\hline 12. FES ARO & 43.9 & 10.04 & & & & & & & 1.0 & .142 & .136 & -.001 \\
\hline 13. FES MRE & 56.2 & 10.96 & & & & & & & & 1.0 & .055 & .003 \\
\hline 14. FES ORG & 49.6 & 9.26 & & & & & & & & & 1.0 & .022 \\
\hline 15. FES CTL & 60.2 & 8.89 & & & & & & & & & & 1.0 \\
\hline
\end{tabular}

Note: INT $=$ Internalizing. EXT $=$ Externalizing. FES $=$ Family Environment Scale. $\mathrm{C}=$ Cohesion. EX $=$ Expressiveness. CON $=$ Conflict. IND $=$ Independence. AO $=$ Achievement Orientation. $\mathrm{ICO}=$ Intellectual-Cultural Orientation. $\mathrm{ARO}=$ Active-Recreational Orientation. $\mathrm{MRE}=$ Moral-Religious Emphasis. $\mathrm{ORG}=\mathrm{Organization} . \mathrm{CTL}=\mathrm{Control}$.

${ }^{*} p<.05,{ }^{* *} p<.01$ 


\section{Data Analysis}

Between-subjects multiple analyses of covariance (MANCOVA) were used to test for treatment effects against a wait-list control group. Post-test scores were adjusted by pre-test scores, which were used as covariates. Data was analyzed for subjects that participated as assigned and subsequent analysis was conducted using Intent To Treat (ITT) analysis to include all subjects originally assigned to receive treatment. Dependent variables included in analyses were: caregiver and teacher reports of internalizing and externalizing problems, caregiver report of attachment problems, and caregiver report of their perception of their family social environment. Attrition rates reduced the power to detect differences. The use of multivariate analyses instead of several univariate analyses accounts for alpha inflation and adjusts the $p$ value as necessary to enhance statistical conclusion validity (Stevens, 2002). ITT analysis was conducted as a more conservative analysis due to a high rate of attrition. 


\section{CHAPTER IV}

\section{RESULTS}

The purpose of this study was to evaluate the effectiveness of Child Parent Relationship Therapy (CPRT) treatment group as delivered in a naturalistic setting to caregivers of children with attachment problems. All children were referred by their primary therapist. This chapter reports the results of the data analyses. It was hypothesized that by caregivers participating in the CPRT treatment group, children would show the following:

- A decrease in externalizing problems,

- An decrease in internalizing problems,

- A decrease in symptoms of attachment, and

- An improvement in perceived family social environment.

The independent variable in this study was the CPRT treatment. The independent variable had two levels (i.e., treatment vs. control). Dependent variables of interest in this study were: (a) Internalizing and externalizing problem as measured by the Teacher Rating Scales (TRS) and Parent Rating Scales (PRS) from the Behavior Assessment System for Children, ${ }^{\text {nd }}$ Edition (BASC-2, Reynolds \& Kamphaus,2004), (b) attachment symptoms as measured by the Randolph Attachment Disorder Questionnaire (RAD-Q, Randolph, 1999), and (c) caregivers' perception of their family social environment as 
measured by the Family Environment Scale (FES, Moos \& Moos, 1994). Six between subjects multivariate analyses of covariance (MANCOVAs) were ran on the data to test the hypotheses. Analyses were conducted for participants who received the full treatment as well as all participants who originally intended to participate; i.e. Intent To Treat (ITT). Analyses were run on three groupings of dependent variables. The groupings of dependent variables were as follows: caregiver report measures including the Internalizing and Externalizing problems on the PRS, BASC-2 and attachment symptoms on the RAD-Q; teacher reports of Internalizing and Externalizing problems on the TRS, BASC-2; and caregiver perception of family social environment scales on the FES. Caregiver reported variables were combined. The teacher reported variables and perceived family social environment were analyzed separately.

\section{Dependent Variables: PRS BASC-2 Internalizing scale, PRS BASC-2 Externalizing scale, and RAD-Q}

Hypotheses 1,3 , and 5 were investigated for participants who received the full treatment as well as all participants who originally intended to participate, i.e. ITT. Two separate between subjects multivariate analyses of covariance (MANCOVAs) were run on the first three dependent variables to include caregiver reports of externalizing behavior, caregiver reports of internalizing problems, and negative symptoms of attachment. Caregiver reports of externalizing problems and internalizing problems were measured with the Behavior Assessment System for Children, $2^{\text {nd }}$ Ed. Parent Report Scale (BASC-2; Reynolds \& Kamphaus, 2004). Attachment symptoms were measured with the Reactive Attachment Disorder Questionnaire (RAD-Q, Randolph, 1999). 


\section{Full treatment analysis.}

Caregiver reports of internalizing problems, externalizing problems, and attachment symptoms were investigated for participants who received full treatment with a between subjects MANCOVA (Tabachnick \& Fidell, 2007). Box's Test of Equality of Covariance Matrices tested the null hypotheses that observed covariance matrices of the dependent variables are equal across groups. The test statistic (Box's $M=10.676$ ) was not significant, $\mathrm{F}(6,6886)=1.59, p=.145$. Because equal variances were assumed, the multivariate test statistic used was Wilks' $\Lambda$ (Tabachnick \& Fidell, 2007). The overall MANCOVA results can be seen in Table 7 and showed multivariate effect that was near but not equal to the traditional value for determining statistical significance for the treatment on the dependent variables with pretest scores as covariates: Wilks' $\Lambda=.762, \mathrm{~F}$ $(3,26)=2.706, p=.066$, as shown in Table 7. The effect size of this measures was moderate, partial $\eta^{2}=.238$ indicating that nearly $24 \%$ of the variance across the three dependent variables can be attributed to the treatment.

Given the relatively small $\mathrm{n}$ of subjects and a moderate effect size, post hoc tests were performed. Post hoc analyses shown in Table 8 indicated the treatment group scored significantly lower on the measures of externalizing problems and symptoms of attachment reported by caregivers than the control group after the treatment occurred. Internalizing problems reported by caregivers were lower for the treatment group but the difference between groups was not significant. As indicated in table 8 there was a moderate effect size for externalizing problems, Cohen's $d=.32$, and a large effect size for negative symptoms of attachment, Cohen's $d=.60$. Cohen indicates a correlation of 0.5 is a large effect size, 0.3 is a moderate effect size, and 0.1 is small effect size (1988). 
Table 7

MANCOVA Results for PCRT Group Treatment; BASC-2 PRS and RAD-Q

\begin{tabular}{ccccc}
\hline & Wilks' $\Lambda$ & $\mathrm{F}(3,26)$ & $p$ & Partial $\eta^{2}$ \\
\hline Treatment & .762 & 2.706 & .066 & .238 \\
\hline
\end{tabular}

Table 8

Post Hoc Between Groups Univariate Analyses with Posttest Means

\begin{tabular}{ccccccccccc}
\hline & \multicolumn{2}{c}{ Treatment $(\mathrm{n}=16)$} & & \multicolumn{2}{c}{ Control $(\mathrm{n}=17)$} & & & \\
\cline { 2 - 3 } & Mean & SD & & Mean & SD & F $(1,33)$ & $p$ & $d$ \\
\hline $\begin{array}{c}\text { RAD-Q } \\
\text { Total }\end{array}$ & 42.75 & 14.07 & 53.82 & 21.84 & 5.885 & $.022^{*}$ & .60 \\
$\begin{array}{c}\text { BASC-2 } \\
\text { PRS Int }\end{array}$ & 58.13 & 10.58 & 60.94 & 15.03 & 3.114 & .089 & .27 \\
$\begin{array}{c}\text { BASC-2 } \\
\text { PRS Ext }\end{array}$ & 64.81 & 8.42 & 69.82 & 10.71 & 7.417 & $.011^{*}$ & .32
\end{tabular}

Note. RAD-Q Total $=$ Randolph Attachment Disorder Questionnaire Total Score. BASC-2 PRS Int = Behavior Assessment System for Children, $2^{\text {nd }}$ Ed., Parent Rating Scales Internalizing Problems. BASC-2 PRS Ext $=$ Behavior Assessment System for Children, $2^{\text {nd }}$ Ed., Parent Rating Scales Externalizing Problems. $p=$ Bonferroni adjustment for multiple comparisons. ${ }^{*}=p<.05 . \mathrm{d}=$ Cohen's $\mathrm{d}$ effect size.

\section{Intent to Treat Analysis.}

Parent reports of internalizing problems, externalizing problems, and attachment symptoms were investigated for all participants who originally intended to participate, i.e. ITT, with a between subjects MANCOVA (Tabachnick \& Fidell, 2007). Box's Test of Equality of Covariance Matrices tested the null hypotheses that observed covariance matrices of the dependent variables are equal across groups. The test statistic (Box's 
$\mathrm{M}=2.123)$ was not significant, $\mathrm{F}(6,11592.453)=, p=.924$. Because equal variances were assumed, the multivariate test statistic used was Wilks' $\Lambda$ (Tabachnick \& Fidell, 2007). The overall MANCOVA results can be seen in Table 9 and showed no significant multivariate effect for the treatment on the dependent variables with pretest scores as covariates: Wilks' $\Lambda=.884, \mathrm{~F}(3,35)=1.53, p=.224$, as shown in Table 9. The effect size of this measure was large, partial $\eta^{2}=.116$ indicating that almost $12 \%$ of the variance across the three dependent variables can be attributed to the treatment. While no overall significance was detected, Post hoc analyses shown in Table 10 indicates that the treatment group scored lower on the measure of externalizing problems reported by caregivers than the control group after the treatment occurred. Given the absence of a multivariate effect, this difference would not be considered significant. The treatment group scored slightly higher than the control group for internalizing problems and slightly lower for negative symptoms of attachment, although neither of these scores was significant. Effect sizes were small for all dependent variables: Attachment symptoms, Cohen's $d=.02$; Internalizing problems, Cohen's $d=.04$; and Externalizing problems, Cohen's $d=.06$. These are small effect sizes based on Cohen's description of a small effect size of 0.1 or smaller (1988).

Table 9

MANCOVA Results for PCRT Group Treatment Intent To Treat; BASC-2 PRS and $R A D-Q$

Wilks' $\Lambda \quad F(3,35) \quad p \quad$ Partial $\eta^{2}$

Treatment

.884

1.53

.224

.116 
Table 10

Post Hoc Between Groups Univariate Analyses with Posttest Means

\begin{tabular}{|c|c|c|c|c|c|c|c|}
\hline & \multicolumn{2}{|c|}{ Treatment $(n=21)$} & \multicolumn{2}{|c|}{ Control $(\mathrm{n}=21)$} & \multirow[b]{2}{*}{$F(1,42)$} & \multirow[b]{2}{*}{$p$} & \multirow[b]{2}{*}{$d$} \\
\hline & Mean & SD & Mean & SD & & & \\
\hline $\begin{array}{c}\text { RAD-Q } \\
\text { Total }\end{array}$ & 48.57 & 18.44 & 49.05 & 22.81 & 2.967 & .093 & .02 \\
\hline $\begin{array}{l}\text { BASC-2 } \\
\text { PRS Int }\end{array}$ & 60.81 & 13.39 & 60.29 & 14.13 & 1.804 & .187 & .04 \\
\hline $\begin{array}{l}\text { BASC-2 } \\
\text { PRS Ext }\end{array}$ & 67.52 & 10.34 & 68.19 & 12.78 & 4.585 & $.039 *$ & .06 \\
\hline
\end{tabular}

Note . RAD-Q Total = Randolph Attachment Disorder Questionnaire Total Score. BASC-2 PRS Int = Behavior Assessment System for Children, $2^{\text {nd }}$ Ed., Parent Rating Scales Internalizing Problems. BASC-2 PRS Ext $=$ Behavior Assessment System for Children, $2^{\text {nd }}$ Ed., Parent Rating Scales Externalizing Problems. $p=$ Bonferroni adjustment for multiple comparisons. ${ }^{*}=p<.05 . \mathrm{d}=$ Cohen's $\mathrm{d}$ effect size.

Multivariate analysis for the variables parent reports of externalizing behavior, parent reports of internalizing problems, and attachment symptoms were examined in Tables 7 and 9. Multivariate analysis for subjects completing the full requirements for participation was near significance for the treatment group, $\mathrm{F}(3,26)=2.706, p=.066$ (see Table 7). Multivariate analysis conducting the more conservative ITT analysis indicated some change for the treatment group but did not show a significant difference posttreatment, $\mathrm{F}(3,35)=1.53, p=.224$ (see Table 9). Post hoc analysis indicated that the direction for change was positive for externalizing problems and negative symptoms of attachment in both analyses and positive for internalizing problems for full treatment subjects but negative for internalizing problems in the ITT analysis. 


\section{Hypothesis one.}

The first hypothesis was that children with attachment problems whose caregivers participated in treatment would have fewer parent reported post-treatment externalizing problems compared to the control group. Post-hoc univariate analyses for full treatment participants showed that there was statistically significant change in externalizing behaviors, $\mathrm{F}(1,33)=7.417, p=.011$ (see Table 8 ). While multivariate analysis did not indicate significance for all participants intended to receive treatment, the post-hoc univariate analysis indicated significance differences for the treatment group posttreatment, $\mathrm{F}(1,42)=4.585, p=.039$ (see Table 10). Taken together the results from full treatment and ITT analysis in this relatively small group of subjects indicated decreases in parent reported externalizing problems for children of caregivers who participated in the CPRT group when compared to the control groups.

\section{Hypothesis three.}

The third hypothesis was that children with attachment problems whose caregivers participated in the CPRT group would have fewer parent reported posttreatment internalizing problems compared to the control group. Post-hoc univariate analyses for full treatment participants indicated that there was a trend, though not a statistically significant one, toward significance in internalizing problems, $\mathrm{F}(1,33)$ $=3.114,(p=.089)$. Multivariate analysis did not indicate significance for all participants intended to receive treatment and the post-hoc univariate analysis indicated no significant difference for the treatment group post-treatment, $\mathrm{F}(1,42)=1.804$ ( $p=.187)$. Post-hoc power analysis indicated that if all other variables were held constant, a sample size of 28 subjects in each group would have produced significant results. Although not significant, 
differences in scores and power analysis indicate that with a larger sample statistical significance would be likely, suggesting that there would be fewer parent reported internalizing problems for the control subjects post-treatment. Taken together the results from full treatment and ITT analysis indicate no significant decreases in parent reported internalizing problems for children of caregivers who participated in the CPRT group when compared to the control groups.

\section{Hypothesis five.}

The fifth hypothesis was that children with attachment problems whose caregivers participated in the CPRT group will exhibit fewer symptoms of attachment compared to the control group. Post-hoc univariate analyses for full treatment participants showed that there was statistically significant change in negative symptoms of attachment, $F(1,33)$ $=5.885, p=.022$ (see Table 8). While multivariate analysis did not indicate significance for all participants intended to receive treatment, the post-hoc univariate analysis indicated that while results were not statistically significant, a modest difference in the means for the treatment group post-treatment was in the intended direction, $\mathrm{F}(1,42)$ $=2.967, p=.093$ (see Table 10). Taken together the results from full treatment and ITT analysis indicate decreases in negative symptoms of attachment for children of caregivers who participated in the CPRT group when compared to the control groups.

\section{Dependent Variables: TRS, BASC-2 Internalizing scale and TRS, BASC-2 Externalizing scale}

Hypotheses 2 and 4 were investigated for participants who received the full treatment as well as all participants who originally intended to participate, i.e. Intent To Treat (ITT). Two separate between subjects multivariate analyses of covariance 
(MANCOVAs) were run on the variables teacher reports of externalizing behavior and teacher reports of internalizing problems. Teacher reports of externalizing problems and internalizing problems were measured with the Behavior Assessment System for Children, $2^{\text {nd }}$ Ed. Parent Report Scale (BASC-2; Reynolds \& Kamphaus, 2004).

\section{Full treatment analysis.}

Teacher reports of internalizing problems and externalizing problems were investigated for participants who received full treatment with a between subjects MANCOVA (Tabachnick \& Fidell, 2007). Box's Test of Equality of Covariance Matrices tested the null hypotheses that observed covariance matrices of the dependent variables are equal across groups. The test statistic (Box's $M=1.221$ ) was not significant, $F(3,99783.919)=.360, p=.782$. Because equal variances were assumed, the multivariate test statistic used was Wilks' $\Lambda$ (Tabachnick \& Fidell, 2007). The overall MANCOVA results can be seen in Table 7 and showed no significant multivariate effect for the treatment on the dependent variables with pretest scores as covariates: Wilks' $\Lambda$ $=.769, \mathrm{~F}(2,16)=2.399, p=.123$. The effect size of this measures was moderate, partial $\eta^{2}=.231$ indicating that $23 \%$ of the variance across the three dependent variables can be attributed to the treatment. Post hoc analyses shown in Table 8 indicated the teachers of children in the treatment group reported more internalizing problems and externalizing problems when compared to the control group; however, these scores were not significantly higher. Based on Cohen's description of effect size (1988), effect sizes for teacher variables were large for externalizing problems, Cohen's $d=.95$, and internalizing problems, Cohen's $d=.95$; although it is still unclear given multivariate analysis was not significant if differences indicate a true relationship between variables. 
Table 11

MANCOVA Results for PCRT Group Treatment; BASC-2 TRS

\begin{tabular}{ccccc}
\hline & & & & \\
& Wilks' $\Lambda$ & F $(2,16)$ & $p$ & Partial $\eta^{2}$ \\
\hline Treatment & .769 & 2.399 & .123 & .231 \\
\hline
\end{tabular}

Table 12

Post Hoc Between Groups Univariate Analyses with Posttest Means

\begin{tabular}{|c|c|c|c|c|c|c|c|}
\hline & \multicolumn{2}{|c|}{ Treatment $(n=11)$} & \multicolumn{2}{|c|}{ Control $(n=10)$} & \multirow[b]{2}{*}{$F(1,21)$} & \multirow[b]{2}{*}{$p$} & \multirow[b]{2}{*}{$d$} \\
\hline & Mean & SD & Mean & $\mathrm{SD}$ & & & \\
\hline $\begin{array}{c}\text { BASC-2 } \\
\text { TRS Int }\end{array}$ & 58.36 & 8.67 & 50.30 & 8.38 & 5.087 & $.038^{*}$ & .95 \\
\hline $\begin{array}{l}\text { BASC-2 } \\
\text { TRS Ext }\end{array}$ & 66.55 & 12.70 & 55.80 & 9.66 & .743 & .401 & .96 \\
\hline
\end{tabular}

Note. BASC2-TRS Int $=$ Behavior Assessment System for Children, $2^{\text {nd }}$ Ed., Teacher Rating Scales Internalizing Problems. BASC-2 TRS Ext = Behavior Assessment System for Children, $2^{\text {nd }}$ Ed., Teacher Rating Scales Externalizing Problems.

$p=$ Bonferroni adjustment for multiple comparisons.

$*=p<.05 . \mathrm{d}=$ Cohen's d effect size.

\section{Intent To Treat analysis.}

Internalizing problems and externalizing problems reported by teachers were investigated for all participants who originally intended to participate, i.e. ITT, with a between subjects MANCOVA (Tabachnick \& Fidell, 2007). Box's Test of Equality of Covariance Matrices tested the null hypotheses that observed covariance matrices of the dependent variables are equal across groups. The test statistic (Box's $M=.536)$ was not 
significant, $F(3,124907.102)=.162, p=.922$. Because equal variances were assumed, the multivariate test statistic used was Wilks' $\Lambda$ (Tabachnick \& Fidell, 2007). The overall MANCOVA results can be seen in Table 9 and showed no significant multivariate effect for the treatment on the dependent variables with pretest scores as covariates: Wilks' $\Lambda=.809, \mathrm{~F}(2,20)=2.359, p=.120$. The effect size of this measure was moderate, partial $\eta^{2}=.191$ indicating that $19 \%$ of the variance across the three dependent variables could be attributed to the treatment. While no overall significance was detected, post hoc analyses shown in Table 10 indicated a trend toward significantly more internalizing problems for the treatment group post-treatment but no trend for the increase on the measure of externalizing problems reported by teachers than the control group after the treatment occurred. Similar to full treatment analysis, effect sizes for the teacher reported variables were large (Cohen, 1988); Internalizing problems, Cohen's $d$ $=.87$ and Externalizing problems, Cohen's $d=1.09$ (see Table 10).

Table 13

MANCOVA Results for PCRT Group Treatment Intent To Treat; BASC-2 TRS

\begin{tabular}{rcccc} 
& Wilks' $\Lambda$ & $\mathrm{F}(2,20)$ & $p$ & Partial $\eta^{2}$ \\
\hline Treatment & .809 & 2.359 & .120 & .191 \\
\hline
\end{tabular}


Table 14

Post Hoc Between Groups Univariate Analyses with Posttest Means

\begin{tabular}{|c|c|c|c|c|c|c|c|}
\hline & \multicolumn{2}{|c|}{ Treatment $(n=13)$} & \multicolumn{2}{|c|}{ Control $(n=12)$} & \multirow[b]{2}{*}{$F(1,25)$} & \multirow[b]{2}{*}{$p$} & \multirow[b]{2}{*}{$d$} \\
\hline & Mean & $\mathrm{SD}$ & Mean & $\mathrm{SD}$ & & & \\
\hline $\begin{array}{l}\text { BASC-2 } \\
\text { TRS Int }\end{array}$ & 56.62 & 9.08 & 49.00 & 8.39 & 4.92 & $.038 *$ & .87 \\
\hline $\begin{array}{l}\text { BASC-2 } \\
\text { TRS Ext }\end{array}$ & 65.85 & 11.72 & 53.75 & 10.02 & .914 & .350 & 1.09 \\
\hline
\end{tabular}

Note. BASC2-TRS Int $=$ Behavior Assessment System for Children, $2^{\text {nd }}$ Ed., Teacher Rating Scales Internalizing Problems. BASC-2 TRS Ext = Behavior Assessment System for Children, ${ }^{\text {nd }}$ Ed., Teacher Rating Scales Externalizing Problems.

$p=$ Bonferroni adjustment for multiple comparisons.

$*=p<.05 . \mathrm{d}=$ Cohen's d effect size.

Multivariate analysis for the variables "teacher reports of externalizing problems" and "teacher reports of internalizing problems" are examined in Tables 7 and 9. The multivariate analysis result for subjects completing the full requirements for participation was not statistically significant for the treatment group, $\mathrm{F}(2,16)=.769, p=.123$ (see Table 7). Multivariate analysis of data regarding the more conservative ITT analysis also indicated no significance for the treatment group, $\mathrm{F}(2,20)=.809, p=.120$ (see Table 9).

\section{Hypothesis two}

The second hypothesis was that children with attachment problems whose caregivers participated in treatment would have fewer teacher reported post-treatment externalizing problems compared to the control group. Multivariate analysis as well as subsequent post-hoc univariate analyses for full treatment participants showed no significant difference in externalizing behaviors, $\mathrm{F}(1,21)=.743, p=.401$ (see Table 8). Multivariate analysis and post-hoc univariate analysis for all participants intended to 
receive treatment indicated no significant differences for the treatment group posttreatment, $\mathrm{F}(1,25)=.914, p=.350$ (see Table 10). However, the direction of change indicated that differences in scores indicate teachers report fewer externalizing problems for the control group post-treatment. Results for full treatment and ITT analysis indicate no significant differences in teacher reported externalizing problems for children of caregivers who participated in the CPRT group when compared to the control groups.

\section{Hypothesis four.}

The fourth hypothesis was that children with attachment problems whose caregivers participated in the CPRT group have fewer teacher reported post-treatment internalizing problems compared to the control group. While multivariate did not indicate a significant difference, post-hoc univariate analyses for full treatment participants showed that there was a trend toward significance increases in internalizing problems, $\mathrm{F}(1,21)=5.087, p=.038$ (see Table 8). Similarly, multivariate analysis did not indicate significance for all participants intended to receive treatment, post-hoc univariate analysis indicated a trend toward significant increase in internalizing problems for the treatment group post-treatment, $\mathrm{F}(1,25)=4.92, p=.038$ (see Table 10). Taken together the results from full treatment and ITT analysis indicate no significant multivariate difference, while univariate analysis suggested a trend toward increases in teacher reported internalizing problems for children of caregivers who participated in the CPRT group when compared to the control groups. Post-hoc power analysis indicated that the sample size was large enough to test for significance. 


\section{Dependent Variable: Family Environment Scales}

The sixth hypothesis was investigated for participants who received the full treatment as well as all participants who originally intended to participate, i.e. ITT. Two separate between subjects multivariate analyses of covariance (MANCOVAs) were run for caregivers' perception of the family social environment. The Family Environment Scales (FES) included the following variables: cohesion, expressiveness, conflict, independence, achievement orientation, intellectual-cultural orientation, activerecreational orientation, moral-religious emphasis, organization, and control. These were measured with the Family Environment Scale (FES, Moos \& Moos, 1994).

\section{Full treatment analysis.}

Caregiver perception of family social environment were investigated for participants who received full treatment with a between subjects MANCOVA (Tabachnick \& Fidell, 2007). Box's Test of Equality of Covariance Matrices tested the null hypotheses that observed covariance matrices of the dependent variables are equal across groups. The test statistic (Box's $M=77.986)$ was not significant, $F(55,3077.366)$ $=.916, p=.651$. Because equal variances were assumed, the multivariate test statistic used was Wilks' $\Lambda$ (Tabachnick \& Fidell, 2007). The overall MANCOVA results can be seen in Table 11. No significant multivariate effect was found for the treatment on the dependent variables with pretest scores as covariates: Wilks' $\Lambda=.458, \mathrm{~F}(10,12)=1.42$, $p=.279$. The effect size of this measures was large, partial $\eta^{2}=.542$ indicating that $54 \%$ of the variance across the three dependent variables can be attributed to the treatment. Post hoc analyses shown in Table 12 indicated that the results had approached significance for several variables on the Family Environment Scales (Moos \& Moos, 
2004). The trend was evident for the treatment group on the measures of independence, achievement orientation, control when compared to the control group after the treatment occurred. Positive trends include higher scores for independence and achievement orientation scales and a lower score on the control scale for the treatment group. Post-hoc power analysis indicated sample size was adequate to determine differences between groups. For social family environment variables with positive trends, the effect size for Control was large (Cohen, 1988), Cohen's $d=.96$, achievement orientation had a medium effect size, Cohen's $d=.61$, and independence had a small effect size, Cohen's $d$ $=.29$.

Table 15 .

MANCOVA Results for PCRT Group Treatment; FES

$$
\text { Wilks' } \Lambda \quad F(10,12)
$$

$p$

Partial $\eta^{2}$

Treatment

.458

1.42

.279

.542 
Table 16.

Post Hoc Between Groups Univariate Analyses with Posttest Means

\begin{tabular}{|c|c|c|c|c|c|c|c|}
\hline & \multicolumn{2}{|c|}{ Treatment $(n=16)$} & \multicolumn{2}{|c|}{ Control $(n=17)$} & \multirow[b]{2}{*}{$F(1,21)$} & \multirow[b]{2}{*}{$p$} & \multirow[b]{2}{*}{$d$} \\
\hline & Mean & SD & Mean & $\mathrm{SD}$ & & & \\
\hline FES C & 43.38 & 16.40 & 46.24 & 14.09 & .277 & .604 & .19 \\
\hline FES EX & 48.06 & 12.93 & 46.00 & 8.26 & .828 & .373 & .19 \\
\hline FES CON & 54.31 & 12.10 & 56.71 & 14.15 & 1.869 & .186 & .18 \\
\hline FES IND & 45.56 & 14.19 & 41.24 & 15.52 & 5.663 & $.027^{*}$ & .29 \\
\hline FES AO & 52.37 & 6.68 & 48.06 & 7.42 & 7.502 & $.012 *$ & .61 \\
\hline FES ICO & 46.81 & 11.25 & 49.71 & 11.23 & .171 & .683 & .26 \\
\hline FES ARO & 44.44 & 10.23 & 45.65 & 11.14 & .431 & .518 & .11 \\
\hline FES MRE & 58.19 & 10.48 & 57.82 & 11.30 & 1.790 & .195 & .03 \\
\hline FES ORG & 47.00 & 8.37 & 51.24 & 10.21 & .216 & .647 & .45 \\
\hline FES CTL & 55.25 & 10.08 & 63.53 & 6.90 & 6.063 & $.023^{*}$ & .96 \\
\hline
\end{tabular}

Note. $\mathrm{FES}=$ Family Environment Scale. $\mathrm{C}=$ Cohesion. $\mathrm{EX}=$ Expressiveness. $\mathrm{CON}=$ Conflict. IND = Independence. $\mathrm{AO}=$ Achievement Orientation. ICO = IntellectualCultural Orientation. ARO $=$ Active-Recreational Orientation. MRE $=$ Moral-Religious Emphasis. $\mathrm{ORG}=$ Organization. $\mathrm{CTL}=$ Control. $p=$ Bonferroni adjustment for multiple comparisons. $*=p<.05$. $\mathrm{d}=$ Cohen's d effect size.

\section{Intent To Treat analysis.}

Caregiver perception of family social environment was investigated for all participants originally intended to receive treatment with a between subjects MANCOVA (Tabachnick \& Fidell, 2007). Box's Test of Equality of Covariance Matrices tested the null hypotheses that observed covariance matrices of the dependent variables are equal 
across groups. The test statistic (Box's $M=52.023)$ was not significant, $F(55,5166.897)$ $=.690, p=.961$. Because equal variances were assumed, the multivariate test statistic used was Wilks' $\Lambda$ (Tabachnick \& Fidell, 2007). The overall MANCOVA results can be seen in Table 13 and indicate no significant multivariate effect for the treatment on the dependent variables with pretest scores as covariates: Wilks' $\Lambda=.671, \mathrm{~F}(10,21)=1.029$, $p=.454$. The effect size of this measures was moderate, partial $\eta^{2}=.329$ indicating that $33 \%$ of the variance across the three dependent variables can be attributed to the treatment. Post hoc analyses shown in Table 14 indicated no significant differences for the treatment group on any family social environment variables. Although multivariate analysis indicate no significant differences between groups, the family social environment scale of Control neared significance, $F(1,30)=3.70, p=.064$, with a large effect size (Cohen, 1988), Cohen's $d=.77$.

Table 17.

MANCOVA Results for PCRT Group Treatment Intent To Treat; FES

\begin{tabular}{ccccc}
\hline & & & & \\
& Wilks' $\Lambda$ & $F(10,21)$ & $p$ & Partial $\eta^{2}$ \\
\hline Treatment & .671 & 1.029 & .454 & .329 \\
\hline
\end{tabular}


Table 18 .

Post Hoc Between Groups Univariate Analyses with Posttest Means

\begin{tabular}{|c|c|c|c|c|c|c|c|}
\hline & \multicolumn{2}{|c|}{ Treatment $(n=21)$} & \multicolumn{2}{|c|}{ Control $(n=21)$} & \multirow[b]{2}{*}{$F(1,30)$} & \multirow[b]{2}{*}{$p$} & \multirow[b]{2}{*}{$d$} \\
\hline & Mean & $\mathrm{SD}$ & Mean & $\mathrm{SD}$ & & & \\
\hline FES C & 42.43 & 14.88 & 46.67 & 13.11 & .451 & .507 & .30 \\
\hline FES EX & 48.62 & 12.00 & 46.10 & 9.65 & .225 & .639 & .23 \\
\hline FES CON & 57.57 & 12.33 & 55.24 & 14.35 & .744 & .395 & .17 \\
\hline FES IND & 43.90 & 13.73 & 41.95 & 14.64 & 2.857 & .101 & .14 \\
\hline FES AO & 50.81 & 6.57 & 50.24 & 8.79 & 2.531 & .122 & .07 \\
\hline FES ICO & 46.00 & 11.36 & 49.43 & 10.43 & .012 & .915 & .31 \\
\hline FES ARO & 43.62 & 10.11 & 44.90 & 10.62 & .157 & .694 & .12 \\
\hline FES MRE & 56.52 & 11.93 & 58.67 & 10.31 & 2.358 & .135 & .19 \\
\hline FES ORG & 47.86 & 8.55 & 51.52 & 10.14 & .347 & .560 & .39 \\
\hline FES CTL & 56.76 & 9.42 & 63.00 & 6.60 & 3.70 & .064 & .77 \\
\hline
\end{tabular}

Note. $\mathrm{FES}=$ Family Environment Scale. $\mathrm{C}=$ Cohesion. $\mathrm{EX}=$ Expressiveness. $\mathrm{CON}=$ Conflict. IND = Independence. $\mathrm{AO}=$ Achievement Orientation. $\mathrm{ICO}=$ IntellectualCultural Orientation. ARO $=$ Active-Recreational Orientation. MRE $=$ Moral-Religious Emphasis. $\mathrm{ORG}=$ Organization. $\mathrm{CTL}=$ Control. $p=$ Bonferroni adjustment for multiple comparisons. ${ }^{*}=p<.05 . \mathrm{d}=$ Cohen's $\mathrm{d}$ effect size.

\section{Hypothesis six.}

The sixth hypothesis was that children with attachment problems whose caregivers participated in the CPRT group would report an improvement of their perceived family social environment compared to the control group. While multivariate 
analysis did not indicate significance for full treatment or ITT analysis, post-hoc univariate analyses for full treatment participants showed that there was statistically significant change in perceived family social scales of: independence, $F(1,21)=5.663$, $p=.027$; achievement orientation, $\mathrm{F}(1,21)=7.502, p=.012$; and control, $\mathrm{F}(1,21)=6.063$, $p=023$ (see Table 12). Post-hoc univariate analysis for all participants originally intended for treatment did show a trend toward significance on the family social environment variable of control, $\mathrm{F}(1,30)=3.7, p=.064$. Taken together the results from full treatment and ITT analysis tended toward improvement in perceived control for families who participated in the CPRT group when compared to the control groups. Post-hoc power analyses indicate the sample size was adequate to find significance for the variables of independence, achievement orientation, and control. The results indicate no overall treatment effect for caregiver perception of family social environment for caregivers of children with attachment problems in the current study. 


\section{CHAPTER V}

\section{DISSCUSSION}

Chapter Five presents a summary of the study and conclusions drawn from the results of data analyses. It offers a discussion of the impact of this treatment for parents and caregivers raising children with attachment problems and offers suggestions for further study.

\section{Summary of Study}

\section{Overview and hypotheses.}

Mental health professionals often face the daunting task of treating children with negative symptoms of attachment. There is a lack of empirically based interventions for attachment disorders, which has historically led to assessment methods and treatment strategies that have not been empirically supported, including some that may be potentially harmful (Boris \& Zeanah, 2005; Files-Hall \& Reddy, 2005; Hanson \& Spratt, 2000; Haugaard \& Hazan, 2004; Minde, 2003; O'Connor \& Zeanah, 2003; Ray, 2006; Ryan, 2004; Sheperis, et. al, 2003). Mental health professionals at Seven Counties Services, Inc. (SCS) often found children with negative symptoms of attachment more difficult to treat and did not believe traditional therapies were effective. Filial therapy was recommended for use with children with attachment disorders and is compatible with recommendations for children with attachment problems (Boris \& Zeanah, 2005; Chaffin et. al, 2006; Files-Hall \& Reddy, 2005; Hanson \& Spratt, 2000; Haugaard \& Hazan, 2004; 
Minde, 2003; O'Connor \& Zeanah, 2003; Ray, 2006; Ryan, 2004; Sheperis, et al. 2003), but had not been empirically supported.

Child Parent Relationship Therapy (CPRT), a structured 10-session model of FT, was implemented in the current study. The time limited structure and the support in past research (Bratton \& Landreth, 1995; Chau \& Landreth, 1997; Costa \& Landreth,1999; Glazer-Waldman, et al., 1992; Glover \& Landreth, 2000; Harris \& Landreth, 1997; Kale \& Landreth, 1999; Lee \& Landreth, 2003, Rennie \& Landreth, 2000; Smith \& Landreth, 2003; Smith \& Landreth, 2004; Stover \& Guerney, 1967; Tew, Landreth, Joiner, \& Solt, 2002; Villarreal, 2008; Yuen, Landreth, \& Baggerly, 2002) were the primary reasons for selecting this model. Research had not been conducted previously to establish the efficacy of CPRT with children who experience problems with attachment. The purpose of this study was to test whether caregiver participation in CPRT group treatment would improve caregiver perception of the family social environment, decrease externalizing and internalizing problems, and decrease negative symptoms of attachment for their children.

\section{Review of methodology.}

Parent Child Relationship Therapy (CPRT, Landreth \& Bratton, 2006), a 10session model of Filial therapy (FT), was implemented in an urban CMHC. Sixty two children were referred for treatment. Of the 62 children referred, 34 of their caregivers agreed to participate. A smaller " $n$ ", smaller effect size, and reduced power would be expected in an efficacy study. This study utilizes CPRT in a natural setting and adds to the external validity of the results. The study used a quasi-experimental design with a pre-test/post-test waitlist control group incorporating random assignment. The subjects 
were referred for participation in the proposed study based on specific criteria of attachment problems (see Appendix A). Six between-subjects multiple analyses of covariance (MANCOVAs) were used to test for treatment effects against a wait-list control group. Post-test scores were adjusted by pre-test scores, which were used as covariates. Data were analyzed for subjects that participated as assigned and subsequent analysis was conducted using Intent To Treat analysis to include all subjects originally assigned to receive treatment. The dependent variables in this analysis were: (a) child internalizing and externalizing problems measured with the Teacher Rating Scale (TRS) and Parent Rating Scale (PRS) from the Behavior Assessment System for Children, $2^{\text {nd }}$ Edition (BASC-2, Reynolds \& Kamphaus, 2004), (b) symptoms of attachment measured with the Randolph Attachment Disorder Questionnaire (RAD-Q, Randolph, 1999), and (c) family members' perceptions of their social environment measured with the Family Environment Scale (FES, Moos \& Moos, 1994). Six separate MANCOVAs were included in the analysis with groupings of dependent variables based on source of information (caregiver or teacher) and the information the variable measured (family or child variable). Analyses were conducted for participants who received the full treatment as well as all participants who originally intended to participate for each grouping of dependent variables.

\section{Findings.}

MANCOVA results for caregiver reported variables of attachment symptoms, externalizing problems, and internalizing problems indicated an overall effect for treatment group versus the waitlist control group for participants who received full treatment. Univariate analysis indicated fewer negative symptoms of attachment, 
externalizing problems and internalizing problems reported by caregivers for the treatment group. Differences between group for negative symptoms of attachment and externalizing problems were statistically significant and differences between groups for internalizing problems neared significance. Post-hoc power analysis indicated that with all other variables held constant, a sample size of 28 subjects in each group would be adequate to find significance for internalizing problems. MANCOVA results for participants who originally intended to participate (ITT) did not indicate an overall treatment effect. Univariate analysis indicated fewer negative symptoms of attachment, externalizing problems, and internalizing problems reported by caregivers for the treatment group, but only externalizing problems produced a significant univariate result.

MANCOVA results for teacher reported variables of externalizing problems and internalizing problems indicated no overall treatment effect for treatment group versus the waitlist control group for participants who received full treatment or for ITT subjects. However, the results with these underpowered analyses were near significance. Post-hoc power analysis indicated sample size was adequate to determine significance. Univariate analysis indicated significant differences for internalizing problems but not for externalizing problems. When comparing group means, teachers reported children whose caregivers participated in the treatment group exhibited more externalizing problems and internalizing problems than the control group following treatment.

MANCOVA results for caregiver's perception of the family social environment indicated no overall treatment effect for treatment versus the waitlist control group when analysis included participants who received full treatment and ITT analysis. While multivariate results were not statistically significant, univariate analysis indicates some 
differences between groups with a trend toward significance. Significant trends included caregiver perceptions of their family social environment on measures of control, independence, and achievement orientation. Post-hoc power analysis indicated sample size was large enough to determine significance at the univariate level. The caregivers reported a decrease in control and increase for independence and achievement orientation.

\section{Findings Related to the Literature}

Therapists for participants complete a checklist related to characteristics and symptoms of attachment disorder (see Appendix A). Based on analysis of the checklists, subjects identified characteristics of attachment indicating the majority of subjects best fit with the DSM category of RAD, Inhibited type (DSM-TR-VI, 2005) and Aggressive Attachment as described by Zeanah, Mammen, and Lieberman (1993). Subjects identified the following attachment characteristics most often: (a) significant disruption in the child's relationship with the primary caregiver (69.7\%), (b) lack of comfort seeking or comfort seeking in ambivalent interactions (69.7\%), and (c) pervasive lack of compliance with primary caregiver or fearful compliance with primary caregiver $(66.7 \%)$. Subjects identified the following characteristics of attachment least often: (a) indiscriminate friendliness across a range of interactions (27.3\%), (b) failure to check back with primary caregiver or unwillingness to leave primary caregiver (24.2\%), (c) willingness to go with strangers without protest or seeking reference from primary caregiver (12.1\%), and (d) immediate engagement with or excessive physical contact with strangers without seeking reference from primary caregiver $(9.1 \%)$. The characteristics of attachment identified by subjects indicate that children who participated in the current study are most closely related to Inhibited RAD (DSM-IV-TR, 2000) and 
aggressive attachment (Zeanah, Mammen, \& Lieberman, 1993) as discussed in the literature review.

There were several differences in the current study implemented in a natural setting compared to most of the studies reviewed in the literature. Training of therapists in the current study differed for each of the therapists involved to include some therapists with a background in play therapy and other therapists who had only these 53 hours of training. Most caregivers in the literature completed all group sessions while the current study included some caregivers that completed 5 of 10 groups. The current study compared subjects in CPRT groups to subjects that were in their choices of services offered in the CMHC. These services included individual therapy, other collateral services, group therapy. The current study collected data from teachers in a public school system which is not organized by geographic region. This led to all subjects having different teachers and most went to different schools. While this may cause some limitations, it adds to the external validity of results. LeBlanc and Ritchie (2001) identified treatment outcomes for play therapy for 42 controlled studies. They reported an average effect size of 0.66 and indicated that if caregivers were involved in treatment, effect sizes were increased by 0.33 standard deviations. Bratton, Ray, Rhine, and Jones (2004) identified treatment outcomes in a meta-analysis that included 93 controlled studies finding an average effect size of 0.80 . Parent-only filial therapy studies had a larger effect size of 1.15. Effect sizes in the current study for variables with significant differences between groups include negative symptoms of attachment $(d=.60)$ and externalizing problems $(d=.32)$ for subjects that completed the study and externalizing symptoms $(d=.06)$ for ITT analysis. These results indicate that effect sizes for the 
current study are not as large compared to previous studies for play therapy. Differences in effect sizes for the current study may be accounted for by the difficulty in treating children with attachment disorders, the attrition rates, and conducting research in a CMHC.

Ceballos and Bratton (2010) found CPRT resulted in significant decreases in child behavior problems for 48 Latino immigrant children; however, this intervention was directed at teachers in the school setting. Garza (2005) did not incorporate caregivers in the intervention, but found a decrease in externalizing behaviors. The current study did not find statistically significant results for teacher reported behavior variables and mean scores indicated changes in a negative direction for the treatment group. This study did not incorporate information about skills learned in the CPRT treatment or provide teachers with any accompanying intervention.

Villerreal (2008) found significant differences between groups on caregiver rated internalizing problems and trends toward significance for externalizing problems. Caregiver reports in this study indicated fewer problems for the treatment group using ttest comparisons for 14 subjects. Teacher rating scales did not find significant results. The current study found significant decreases on caregiver rated externalizing problems and trends toward significant changes for internalizing problems. These results were similar to the study presented above which received referrals from the school but did not focus on any specific mental health problems.

Current literature for children with attachment disorders does not address effectiveness of CPRT treatment; however, many studies were found that investigated CPRT for populations at risk for attachment problems. Tew, Landreth, Joiner, and Solt 
(2002), Smith and Landreth (2003), and Costa and Landreth (1999) used the Child Behavior Checklist (CBCL) and found a significant decrease in the number of behavior problems. Harris and Landreth (1997) found significant decreases in behavior problems on the Filial Problem Checklist. The current study found significant changes in externalizing problems for children whose caregivers completed the CPRT treatment, and is the first to incorporate the Behavior Assessment System for Children, $2^{\text {nd }}$ Edition (Reynolds \& Kamphaus, 2004) for CPRT with caregivers of children with attachment problems. While effect sizes for the current study are smaller, significant changes in symptoms of attachment and externalizing behavior are promising taking into account that children with attachment problems are often very difficult to treat.

\section{Limitations and Suggestions for Future Practice and Research}

The limitations of this study offer suggestions for future research. First, this study took place at one Seven Counties Services, Inc. site in one Community Mental Health Center (CMHC). Results are limited to clients served in this urban CMHC in a narrow geographic region. Replication studies in other areas and with a larger sample size would increase ability to generalize to other populations and add confidence to the findings.

Second, this study had a smaller number of participants than were called for in the original design. This reduced the power to find statistically significant changes. Even with this limitation, this study showed significant change in measures of negative symptoms of attachment and caregiver reported externalizing problems. A smaller " $n$ ", a smaller effect size and reduced power would be expected in an efficacy study. A similar study with a larger number of participants and the same effect sized would show greater 
changes in externalizing problems and negative symptoms of attachment and may increase effect on additional variables.

Third, difficulties with diagnosis for attachment disorders were a limitation for the current study. As research adds to the understanding of diagnosing attachment disorders and the DSM diagnosis changes for attachment, this study may need to be evaluated to determine if characteristics identified by subjects are accurate. It may be helpful in future studies to adjust diagnostic criteria. It may also be beneficial to collect data on positive characteristics of attachment to measure outcomes for treatment groups. Research in this area could help make more cost-effective decisions as to whom to offer the program.

Forth, the current study included data from a secondary source; however, the low numbers of teacher data collected indicate this data must be interpreted with caution. Future research should be conducted to improve usefulness of a secondary source of information. Improvements in data collection procedures would further validate and add significance to findings. It was not feasible in the current study because subjects attended many different schools and all subjects had different teachers; however, incorporating a school component may increase positive effects from future studies that include teacher variables.

Fifth, longitudinal data were not gathered for the majority of subjects. It would be helpful to learn if gains are maintained and for how long after the conclusion of treatment. Longitudinal studies could also analyze if this program impacts behavior in the school setting if changes are maintained in the home. If long-term behavioral changes were made, the skills learned in this program might impact families through generations. 
Sixth, this study used a wait-list control group with many of those subjects not receiving the intervention. It was the intention of this study to use a waitlist control group to allow comparisons before and after treatment as well as the ethical obligation to offer all subjects treatment. The study also collected data on additional services in an attempt to compare CPRT with traditional services. Seventeen children in the waitlist control group participated individual therapies compared to 9 children from the treatment group. This could account for lower effect sizes compared to meta-analysis studies that indicate many study compared treatment groups to no treatment. Comparisons for all other therapies were similar in attendance to include family therapy services, child group therapy, and other parent services. It would strengthen future studies to compare this CPRT treatment to a specific treatment with similar theoretical advantages for children with attachment problems. This may help to determine if changes are due to involvement in CPRT groups or if other, even less-resource intensive alternatives would also decrease negative symptoms of attachment and externalizing problems.

\section{Implications}

Although the study was under-powered and change did not occur in the expected direction on expected measures, significant changes were found. Negative symptoms of attachment decreased and caregivers reported fewer externalizing problems for the treatment group but not the control group. The treatment group also neared significance on caregiver reported internalizing problems and the family social environment scales of control, achievement orientation, and independence.

The results of this study support the idea that CPRT, which is recommended by The Child Psychotherapy Treatment Planner (Jongsma, Peterson, McInnis, \& Bruce, 
2006) for treatment of attachment problems, has the potential to affect change for families. Additional studies to further validate CPRT and to support generalization would add confidence in this finding. Results indicate that CPRT for children with attachment problems would be a good alternative for clinicians who are currently treating attachment problems with therapeutic interventions designed for other disorders that do not include caregivers or have not been empirically validated for attachment problems.

Results of teacher reported variables indicating increases in internalizing and externalizing problems for the treatment group when compared to the wait-list control group are an area of concern. The negative direction of these results for teacher variables may indicate that future research needs to investigate these variables in a more controlled setting, look more closely at time constraints, or identify additional interventions for teachers that would complement the family intervention.

Though originally hypothesized that teacher reports of externalizing and internalizing variables would show an overall treatment effect, intervention in one setting do not always improve problems in additional settings. I did not predict the negative direction of result. There would be some concern with implementing CPRT without incorporating a school intervention for children who are also having difficulty with behavior in the classroom. However, this recommendation would be best practice for any child with behavior concerns in more than one setting.

There is little evidence for prevalence of attachment disorders and for effective treatment for this population. However, clinicians often report that children with symptoms of attachment are in therapy longer and have less effective outcomes. CPRT may prove a less resource-intensive treatment and can be helpful for caregivers of 
children who display symptoms of attachment disorders. This treatment is associated with focus on a relationship with the primary caregiver which may have long term effects in social relatedness with the family and may improve relationships outside the home. It is hopeful to find that a 10-session treatment program can affect change for symptoms of attachment and caregiver reported externalizing problems in a population so difficult to treat.

\section{Conclusions}

This study evaluated a parent collateral service CPRT group program implemented in a Community Mental Health Center. Participants of the 10-session treatment showed gains in caregiver reported symptoms of attachment and externalizing problems. Although teacher reported variables did not improve with CPRT treatment, additional research would need to be conducted before CPRT was considered ineffective in additional settings. This brief therapeutic program seems to have some benefit and may be a more cost effective method of addressing problems exhibited by children with attachment problems. Future CPRT studies investigating effectiveness for children with attachment problems may benefit from incorporation of the following changes: (a) comparison with other specific treatment for attachment, (b) incorporate information for teachers on treatment or incorporate a teacher component of treatment, (c) increase number of participants, (d) investigate positive attachment characteristics, or (e) increase collection of longitudinal data. Overall this study adds to the growing literature that CPRT, delivered in a naturalistic setting, can affect positive change in children with negative symptoms of attachment. 


\section{REFERENCES}

Abidin, R. R. (1986). Parenting Stress Index (PSI) manual, (2nd Ed.). Charlottesville, VA: Pediatric Psychology Press.

Ainsworth, M. (1989). Attachments beyond infancy. American Psychologist, 44(4), 709716.

Ainsworth, M., Blehar, M., Waters, E., \& Wall, S. (1978). Patterns of Attachment: A psychological study of the strange situation. Lawrence Erlbaum Associates; Hillsdale, NJ.

Allison, J. (2001). Test review of the Parenting Stress Index. From B. S. Plake \& J. C. Impara (Eds.), The Fourteenth Mental Measurements Yearbook [Electronic version]. Retrieved, June 21, 2005, from the Buros Institute's Test Reviews Online website: $\underline{\text { http://www.unl.edu/buros }}$

American Psychiatric Association. (1980). Diagnostic and Statistical Manual of Mental Disorders $\left(3^{\text {rd }}\right.$ Ed.) Washington, DC: American Psychological Association American Psychiatric Association. (2000). Diagnostic and statistical manual of mental disorders (4th ed., TR). Washington, DC: Author.

Bagner, D. \& Eyberg, S. (2007). Parent-child interaction therapy for disruptive behavior in children with mental retardation: A randomized controlled trial. Journal of Clinical Child and Adolescent Psychology, 36, 418-429.

Bavin-Hoffman, R., Jennings, G., \& Landreth, G. (1996). Filial therapy: Parental of the process. International Journal of Play Therapy, 5(1), 45-58. 
Becker-Weidman, A. (2006). Treatment for children with trauma-attachment disorders: Dyadic developmental psychotherapy. Child and Adolescent Social Work Journal, $23(2), 147-171$.

Boris, N., Hinshaw-Fuselier, S., Smyke, A., Scheeringa, M., Heller, S, \& Zeanah, C. (2004). Comparing criteria for attachment disorders: Establishing reliability and validity in high-risk samples. American Academy of Child and Adolescent Psychiatry, 43(5), 568-577

Boris, N. \& Zeanah, M. (1999). Disturbances and disorders of attachment in infancy: An overview. Infant Mental Health Journal, 20(1), 1-9.

Boris, N. \& Zeanah, M. (2005). Practice parameters for the assessment and treatment of children and adolescents with Reactive Attachment Disorder of infancy and early childhood. American Academy of Child and Adolescent Psychiatry, 44 (11), 12061219.

Boris, N., Zeanah, C., Larrieu, J., Scheeringa, M., \& Heller, S. (1998). Attachment disorders in infancy and early childhood: A preliminary investigation of diagnostic criteria. American Journal of Psychiatry, 155(2), 295-297.

Bowlby, J. (1988). Developmental psychiatry comes of age. The American Journal of Psychiatry, 145, 1-10.

Bowlby, J. (1968) Attachment. New York, NY: Basic Books.

Bowlby, J. (1980). Attachment and loss. New York, NY: Basic Books.

Bratton, S. \& Landreth, G. (1995). Filial therapy with single : Effects on parental acceptance, empathy, and stress. International Journal of Play Therapy, 4(1), 6180 . 
Bratton, S.C., Ray, D., Rhine, T., \& Jones, L. (2005). The efficacy of play therapy with children: A meta-analytic review of treatment outcomes. Professional Psychology: Research and Practice, 36 (4), 376-390.

Carlson, E. A. (1998). A prospective longitudinal study of attachment disorganization/disorientation. Child Development, 69(4), 1107-1128.

Carlson, E., \& Sroufe, L. (1995). The contribution of attachment theory to developmental psychopathology. In D. Cicchetti \& D. Cohen (Eds.), Developmental processes and psychopathology: Volume 1. Theoretical perspectives and methodological approaches (pp. 581-617). New York: Cambridge University Press.

Ceballos, P.L. \& Bratton, S.C. (2010). Empowering Latino families: Effects of a culturally responsive intervention for low-income immigrant Latino parents of children's behavior and parental stress. Psychology in the Schools, 47 (8), 761775.

Chaffin, M., Hanson, R., Saunders, B. E., Nichols, T., Barnett, D., Zeanah, C., Berliner, L., Egeland, B., Newman, E., Lyon, T., LeTourneau, E., \& Miller-Perrin, C. (2006). Report of the APSAC task force on attachment therapy, Reactive Attachment Disorder, and attachment problems. Child Maltreatment, 11 (1), 7689.

Chase, R., \& Eyberg, S. (2008). Clinical presentation and treatment outcome for Children with Comorbid Externalizing and Internalizing Symptoms. Journal of Anxiety Disorders, 22. 273-282. 
Chau, I. \& Landreth, G. (1997). Filial therapy with Chinese parents: Effects on parental empathic interactions, parental acceptance of child and parental stress. International Journal of Play Therapy, 6(2), 75-92.

Cohen, J. (1988). Statistical power analysis for the behavioral sciences (2nd Ed.). New Jersey: Lawrence Erlbaum.

Cornell, T. \& Hamrin, V. (2008). Clinical interventions for children with attachment problems. Journal of Child and Adolescent Psychiatric Nursing, 21(1), 35-47.

Costas, M \& Landreth, G. (1999). Filial therapy with nonoffending parents who have been sexually abused. International Journal of Play Therapy, 8(1), 43-66.

Del Carmen, R. \& Huffman, L. (1996). Epilogue: Bridging the gap between research on attachment and psychopathology. Journal of Consulting and Clinical Psychology, $64(2), 291-294$

Fairchild, S. (2006). Understanding attachment: Reliability and validity of selected attachment measures for preschoolers and children. Child and Adolescent Social Work Journal, 23(2), 235-261.

Files-Hall, T. \& Reddy, L. (2005). Present status and future directions for empirically based play interventions for children. Reddy, L.A., Files-Hall, T.M., \& Schaefer, C.E. (Eds.) Empirically Based Play Interventions For Children. American Psychological Association; Washington, DC.

Ginsberg, B. (1976). Parents as therapeutic agents: The usefulness of filial therapy in a community mental health center. American Journal of Community Psychology, $4(1), 47-55$. 
Ginsberg, B. (2002). The power of filial relationship enhancement therapy as an intervention in child abuse and neglect. International Journal of Play Therapy, $11(1), 65-78$.

Glazer-Waldman, H., Zimmerman, J., Landreth, G., \& Norton, D. (1992). Filial therapy: An intervention for parents of children with chronic illness. International Journal of Play Therapy, 1, 31-42.

Glover, G. \& Landreth, G. (2000). Filial therapy with Native Americans on a flathead reservation. International Journal of Play Therapy, 9(2), 57-60.

Goodwin, C. (2003). Filial therapy with court ordered parents of maltreated children: A multiple case study. Dissertation, Virginia Polytechnic Institute and State University, Blacksburg, Virginia.

Greenburg, M., Speltz, M., and DeKlyen, M. (1993). The role of attachment in the early development of disruptive behavior problems. Development and Psychopathology, $5,191-213$.

Greenberg M. \& Speltz M. (1988). Attachment and the ontogeny of conduct problems. Belsky J. \& Nezworski T. (Eds.) Clinical Implications of Attachment, 177-218. Hillsdale, NJ: Erlbaum.

Guerney, L. (2000). Filial therapy into the $21^{\text {st }}$ century. International Journal of Play Therapy, 9(2), 1-17.

Hanson, R. \& Spratt, E. (2000). Reactive attachment disorder: What we know about the disorder and implications for treatment. Child Maltreatment, 5(2), 137-145.

Hall, S. \& Geher, G. (2003). Behavioral and personality characteristics with reactive attachment disorder. Journal of Psychology, 137(2), 145-163. 
Harris, Z. \& Landreth, G. (1997). Filial therapy with incarcerated mothers: A five week model. International Journal of Play Therapy, 6(2), 53-73.

Haugaard, J. \& Hazan, C. (2004). Recognizing and treating uncommon behavioral and emotional disorders in children and adolescents who have been severely maltreated: Reactive Attachment Disorder. Child Maltreatment, 9 (2), 154-160.

Herschell, A. \& McNeil, C. (2005). Parent-child interaction therapy for children experiencing externalizing behavior problems. Reddy, L.A., Files-Hall, T.M., \& Schaefer, C.E. (Eds.) Empirically Based Play Interventions For Children. American Psychological Association; Washington, DC.

Hinshaw-Fusilier, S., Boris, N. \& Zeanah, C. (1999). Reactive attachment disorder in maltreated twins. Infant Mental Health Journal, 20(1), 42-59.

Hughes, D. (1998). Building the Bonds of Attachment: Awakening love in deeply troubled children. Lanham, MD: Rowman \& Littlefield, Inc.

Jongsma, A., Peterson, L., McInnis, W., \& Bruce, T. (2006). The Child Psychotherapy Treatment Planner, $4^{\text {th }}$ Ed. John Wiley \& Sons: Hoboken, NJ.

Kale, A. \& Landreth, G. (1999). Filial therapy with parents of children experiencing learning difficulties. International Journal of Play Therapy, 8(2), 35-56.

Kaduson, H. \& Schaefer, C. (2006). Short-term play therapy for children (2nd ed.), 388 pp. New York, NY: Guilford Press.

Landreth, G. \& Bratton, S. (2006). Child Parent Relationship Therapy (CPRT): A 10Session Filial Therapy Model. New York: Routledge.

LeBlanc, M. \&Ritchie, M. (2001). A meta-analysis of play therapy outcomes. Counseling Psychology Quarterly, 14 (2), 149-163. 
Lee, M. \& Landreth, G. (2003). Filial therapy with immigrant Korean parents in the United States. International Journal of Play Therapy, 12(2), 67-85.

Levy, T. (2000). Handbook of attachment interventions, 289 pp. San Diego, CA: Academic Press.

Levy, M. \& Orlans, M. (1998). Attachment, trauma, and healing: Understanding and treating attachment disorder in children and families. Child Welfare League of America, Inc.; Washington, DC.

Lieberman, A., \& Pawl, J. (1988). Clinical applications of attachment theory. Belsky, J., Nezworski, T. (Eds). Clinical implications of attachment. (pp. 327-351). Hillsdale, NJ: Lawrence Erlbaum Associates, Inc.

Loeber, R., Lahey, B., \& Thomas, C. (1991). Diagnostic conundrum of oppositional defiant disorder and conduct disorder. Journal of Abnormal Psychology, 100(3), 379-390.

Lynam, D. (1996). Early identification of chronic offenders: Who is the fledging psychopath? Psychological Bulletin, 120(2), 209-234.

Lyons, T.H. (2007). Attachment theory and Reactive Attachment Disorder: Theoretical perspectives and treatment implications. Journal of Child and Adolescent Psychiatric Nursing, 20(1), 27-39.

Lyons-Ruth, K. (1996). Attachment relationships among children with aggressive behavior problems: The role of disorganized early attachment patterns. Journal of Consulting and Clinical Psychology, 64 (1), 64-73. 
Lyons-Ruth, K., Alpern, L., \& Repacholi, B. (1993). Disorganized infant attachment classification and maternal psychosocial problems as predictors of hostileaggressive behavior in the preschool classroom. Child Development, 64, 572-585.

MacMillan, H., Fleming, J., Streiner, D., Lin, E., Boyle, M., Jamieson, E., Duku, E., Waish, C., Wong, M., \& Beardslee, W. (2001). Childhood abuse and lifetime psychopathology in a community sample. American Journal of Psychiatry, 158, 1878-1883.

Main, M, \& Solomon, J. (1986). Discovery of an insecure-disorganized/disoriented attachment pattern. Brazelton, T., Yogman, M. (Eds). Affective development in infancy. (pp. 95-124). Westport, CT: Ablex Publishing.

Marvin, R. S. \& Whelan, W. F. (2003). Disordered attachments: Toward evidencedbased clinical practice. Attachment \& Human Development, 5 (3), 283-288.

Mancini, J.A. (2001). Test review of the Family Environment Scale. From B. S. Plake \& J. C. Impara (Eds.), The Fourteenth Mental Measurements Yearbook [Electronic version]. Retrieved, June 21, 2005, from the Buros Institute's Test Reviews Online website: $\underline{\mathrm{http}: / / \mathrm{www} . u n l . e d u / b u r o s}$

Merenda, P.F. (1996). BASC: Behavior assessment system for children. Measurement and Evaluation in Counseling and Development, 28 (4), 229-232.

Minde, K. (2003). Assessment and treatment of attachment disorders. Current Opinions in Psychiatry, 16, 377-381.

Minde, K. (2003). Attachment problems as a spectrum disorder: Implications for diagnosis and treatment. Attachment \& Human Development, 5 (3), 289-296. 
Moos, R. H., \& Moos, B. S. (1994). Family Environment Scale manual (3rd ed.). Palo Alto, CA: Consulting Psychologists Press.

Morgan, P. (2004). Frequency of RAD diagnosis and attachment disorder in community mental health agency clients. University of Louisville, pp. 143, AAT 3134192.

O’Connor, T., Marvin, R., Rutter, M., Olrick, J., Britner, P., \& The English and Romanian adoptees study team. (2003). Child-parent attachment following early deprivation. Development and Psychopathology, 15, 19-38.

O'Connor, T., Rutter, M., \& The English and Romanian adoptees study team. (2000). Attachment disorder behavior following early severe deprivation: Extension and longitudinal follow-up. Journal of the American Academy of Child and Adolescent Psychiatry, 39(6), 703-712.

O'Connor, T. \& Zeanah, C. (2003). Attachment disorders: Assessment strategies and treatment approaches. Attachment and (\&) Human Development, 5 (3), 223-244.

O'Connor, T. \& Zeanah, C. (2003). Current perspectives on attachment disorders: Rejoinder and synthesis. Attachment and (\&) Human Development, 5 (3), 321 326.

Randolph, E. (1999). Randolph Attachment Disorder Questionnaire (2nd Ed.). Evergreen, CO.: Attachment Center Press.

Ray, D. (2006). Evidence-based play therapy. Schaefer, C. \& Kaduson, H. (Eds.) Contemporary Play Therapy: Theory, Research, and Practice. New York, NY: Guilford Publications.

Rennie, R. \& Landreth, G. (2000). Effects of filial therapy on parent and child behaviors. International Journal of Play Therapy, 9(2), 19-37. 
Reynolds, C., \& Kamphaus, R. (2004). BASC-2: Behavior assessment system for children, second edition manual. Circle Pines, MN: American Guidance Service.

Reynolds, C.R. \& Kamphaus, R.W. (2004). Behavior assessment system for children (2 ${ }^{\text {nd }}$ ed.). Test Review. Assessment for Effective Intervention, 32 (2), 121-124.

Richters, M., \& Volkmar, F. (1994). Reactive attachment disorder of infancy or early childhood. Journal of the American Academy of Child \& Adolescent Psychiatry, 33(3), 328-332.

Rosenstein, D. \& Horowitz, H.A. (1996). Adolescent attachment and psychopathology. Journal of Consulting and Clinical Psychology, 64(2), 244-253.

Rutter, M. (1997). Clinical implications of attachment concepts: Retrospect and prospect. In Atkinson, L., Zucker, K. (Eds). Attachment and psychopathology. (pp. 17-46). New York, NY: Guilford Press.

Rutter, M., Kreppner, J. \& Sonuga-Barke, E. (2009). Emanuel Miller lecture: Attachment insecurity, disinhibited attachment, and attachment disorders: Where do research findings leave us? The Journal of Child Psychology and Psychiatry, 50 (5), 529543.

Ryan, V. (2004). Adapting non-directive play therapy for children with attachment disorders. Clinical Child Psychology and Psychiatry, 9(1), 75-87.

Schreiber, R \& Lyddon, W. (1998). Parental bonding and current psychological functioning among childhood sexual abuse survivors. Journal of Counseling Psychology, 45(3), 358-362.

Schwartz, E. \& Davis, A. (2006). Reactive attachment disorder: Implications for school readiness and school functioning. Psychology in the Schools, 43 (4), 471-479. 
Shadish, W., Cook, T., \& Campbell, D. (2002). Experimental and quasi-experimental designs for generalized causal inference. Houghton-Mifflin; Boston, CO.

Sheperis, C., Doggett, R., Hoda, N., Blanchard, T., Renfro-Michel, E., Holdiness, S., \& Schlagheck, R. (2003). The development of an assessment protocol for Reactive Attachment Disorder. Journal of Mental Health Counseling, 25 (4), 291-310.

Smith, D. \& Landreth, G. (2004). Filial therapy with teachers of deaf and hard of hearing preschool children. International Journal of Play Therapy 13(1), 13-33.

Smith, N \& Landreth, G. (2003). Intensive filial therapy with child witnesses of domestic violence: A comparison with individual and sibling group play therapy. International Journal of Play Therapy, 12(1), 67-88.

Sroufe, L. (2005). Attachment and development: A prospective, longitudinal study from birth to adulthood. Attachment \& Human Development, 7(4), 349-367.

Sroufe, L., Fox, N., \& Pancake, V. (1983). Attachment and dependency in developmental perspective. Child Development, 54, 1615-1627.

Stover, L. \& Guerney, B. (1967). The efficacy of training procedures for mothers in filial therapy. Psychotherapy: Theory, Research, and Practice, 4(3), 110-115.

Tabachnick, B. \& Fidell, L. (2007). Using Multivariate Statistics (5th ed.). Boston: Pearson International Edition.

Timmer, S., Urquiza, A., Herschell, A., McGrath, J., Zebell, N., Porter, Alissa L., Vargas, E. (2006). Parent-Child Interaction Therapy: Application of an Empirically Supported Treatment to Maltreated Children in Foster Care. Child Welfare Journal, 85(6), 919-939. 
Tew, K, Landreth, G., Joiner, K., \& Solt, M. (2002) Filial therapy with parents of chronically ill children. International Journal of Play Therapy, 11(1), 79-100.

Thomas, R. \& Zimmer-Gembeck M. (2007). Behavioral outcomes of Parent-Child Interaction Therapy and triple p-positive parenting program: A review and metaanalysis. Journal of Abnormal Child Psychology, 35(3), 475-496.

Villarreal, C. (2008). School-based Child Parent Relationship Therapy (CPRT) with Hispanic Parents. (Doctoral Dissertation, Regent University). Dissertation Abstacts International, 162, AAT 3302011.

Wilder, L.K. \& Sudweeks, R.R. (2003). Reliability of ratings across studies of the BASC. Education and Treatment of Children, 26 (4), 382-399.

World Health Organization (1992). The ICD-10 classification of mental health and behavioral disorders in infancy: Clinical descriptions and diagnostic guidelines. Geneva: WHO press.

Yuen, T., Landreth, G., \& Baggerly, J. (2002). Filial therapy with immigrant Chinese families. International Journal of Play Therapy, 11(2), 63-90.

Zeanah, C. (1996). Beyond insecurity: A reconceptualization of attachment disorders in infancy. Journal of Consulting and Clinical Psychology, 64(1), 42-52.

Zeanah, C., Mammen, O., \& Lieberman, A. (1993). Disorders of attachment. Zeanah, C. (Ed). Handbook of infant mental health. , 332-349; New York, NY: Guilford Press.

Zeanah, C.H. \& Smyke, A.T. (2008). Attachment disorders in family and social contexts. Infant Mental Health Journal, 29(3), 219-233. 


\section{Appendix A}

\section{Children with Attachment Problems}

Therapist Checklist for Inclusion in Child Parent Relationship Therapy Research

Directions: Place a checkmark next to any characteristics identified for your client that you have observed or that have been reported to you by child's caregiver, teachers, or other helping professionals.

A history of removal from the primary caregiver

Significant disruption in the child's relationship with the primary caregiver

Significant lack of affection with primary caregiver

Indiscriminate friendliness across a range of interactions

Lack of comfort seeking or comfort seeking in an ambivalent manner

Excessive dependence on caregiver which is developmentally inappropriate

Inability to seek support when needed as developmentally appropriate

Pervasive lack of compliance with caregiver or fearful compliance with caregiver

Failure to check back with caregiver or complete unwillingness to leave caregiver

Lack of affection or avoidance or failure to resolve distress following separation

Willingness to go with stranger without protest or seeking reference from caregiver

Immediate engagement with or excessive physical contact with strangers without seeking reference from caregiver 
Appendix B

\section{PARENT INFORMATION FORM}

Please complete the following information about the household in which the child participating in the study lives most of the time (greater than half the time).

1. How many adults ( 18 or older) including yourself live in the household?

2. How many children (under 18) including the child being studied live in the household?

3. Think of all of the income from persons living in the same house as the child being studied. Which category below best describes your household income for the last 12 months?
a. $\$ 8,859$ or below
b. $\$ 8,860-\$ 11,939$
c. $\$ 11,940-\$ 15,019$
d. $\$ 15,020-\$ 18,099$
e. $\$ 18,100-\$ 21,179$
f. $\$ 21,180-\$ 24,259$
g. $\$ 24,260-\$ 27,339$
h. $\$ 27,340-\$ 30,419$
i. $\$ 30,420-\$ 49,999$
j. $\$ 50,000-\$ 74,999$
k. $\$ 75,000-\$ 100,000$
l. $\$ 100,000$ or above

4. In terms of your "typical" household income, how would you describe your income for the last 12 months?

a. Much less than usual.

b. Somewhat less than usual

c. About the same as usual

d. Somewhat more than usual

e. Much more than usual

5. In the last 12 months, did your household receive any of the following kinds of income? Please check all that apply

Unemployment compensation Disability (Workman's Compensation or Social Security) Welfare (including Aid to Families with Dependent Children) Support or alimony from ex-spouse Food stamps 
Medicaid

Public housing

WIC (Women, Infants, and Children) food vouchers

Other public assistance (specify)

6. Please indicate the level of education completed by the child's mother or mother figure living in the household.

$\begin{array}{llll}\text { Primary grades } & 6 & 7 & 8\end{array}$

$\begin{array}{lllll}\text { High School } & 9 & 10 & 11 & 12\end{array}$

POST HIGH SCHOOL (Please check all that apply) attended received degree

Vocational school

2-year college

4-year college

Graduate/professional school (above a 4-year degree)

(specify)

Other (specify; be specific)

(specify)

7. Please indicate the level of education completed by the child's father or father figure living in the household.

Primary grades

High School

$\begin{array}{llll} & 6 & 7 & 8 \\ 9 & 10 & 11 & 12\end{array}$

POST HIGH SCHOOL (Please check all that apply) attended received degree

Vocational school

2-year college

4-year college

Graduate/professional school (above a 4-year degree)

(specify)

Other (specify; be specific)

(specify) 
8. Please describe the occupation of the child's mother or mother figure living in the home. (Be specific)

9. Please describe the occupation of the child's father or father figure living in the home. (Be specific)

10. Which of the following descriptions best describe the work pattern of the primary support person in the household?

Not working due to family care responsibilities

Not working due to own health problems or disabilities

Unemployed because can't find work

Works whenever work is available

Works steady or regular part-time job

Works full-time job

11. What is the age of the child's mother?

12. What is the age of the child's father? 


\section{Appendix C}

Therapist Checklist for Clients participating in

Child Parent Relationship Therapy research

Please place a check beside ALL services that your client and their caregivers received while participating in group CPRT group and list the number of hours for each service provided.

Check all services received while in waitlist control group and list number of hours for each service provided:

Individual therapy hours

Child group services hours Individual parent collateral services hours Parent collateral group services other than CPRT group hours

Family Therapy hours In-Home Therapeutic Services hours Impact Services hours School-Based Therapeutic Services

Psychotropic Medication hours hours

Check all adjunctive services received while participating in CPRT group: Individual therapy hours Child group services hours Individual parent collateral services hours Parent collateral group services other than CPRT group Family Therapy hours In-Home Therapeutic Services hours Impact Services hours School-Based Therapeutic Services Psychotropic Medication hours hours hours 


\section{CURRICULUM VITAE Margaret C. Sergeant}

Mailing Address:

6170 Sonoma Court

Owensboro, Ky 42303

\section{Contact Number:}

(502) 445-9879 (cell)

E-mail: magscares@yahoo.com

\section{Education:}

University of Louisville

Louisville, Kentucky

Doctoral Student, College of Education and Human Development

Counseling Psychology, Ph.D.

August 2003 - Present

Comprehensive exams completed: March 2006

Dissertation topic: Efficacy of Child Parent Relationship Therapy for Caregivers

of Children with Attachment Problems

M.Ed., College of Education and Human Development

Masters of Education, Counseling and Personnel Services

Specialization in Elementary School Counseling

December 2001

\section{Spalding University}

Louisville, Kentucky

B.A., College of Education

Bachelor of Arts, Elementary Education

Graduation: May 1995

\section{Honors:}

Spalding University Dean's List, Undergraduate

Graduated with honors, M.Ed.

Alpha Delta Kappa, Alpha Chapter Scholarship 


\title{
Employment:
}

Oct 2009-present

\author{
Behavior Associates, Inc. \\ 4846 Ridge Creek Rd., Owensboro, KY 42303 \\ Position: Behavior Specialist \\ Supervisor: Stanley Bittman, Ph.D
}
Responsibilities: Provide monthly data collection of behaviors for clients with a primary diagnosis of mental retardation. Data collection includes observations, staff interviews, and compiling of monthly behavior counts. I work with adult and adolescent clients in an ICFMR-DD and community programs. I provided training and supervision of new behavior specialists. Online course work toward certification in Applied Behavior Analysis.

Oct 2002-June 2008

\author{
Behavior Associates, Inc. \\ 4846 Ridge Creek Rd., Owensboro, KY 42303 \\ Position: Behavior Specialist \\ Supervisor: Stanley Bittman, Ph.D
}

Responsibilities: Provide monthly data collection of behaviors for clients with a primary diagnosis of mental retardation. Data collection includes observations, staff interviews, and compiling of monthly behavior counts. I worked with adult clients for two years and adolescents for three years. I provided support staff with behavior training and made recommendations to the treatment team when necessary.

\section{Sept 1996- May 2003}

\author{
Price Elementary \\ Jefferson County Public Schools \\ 5001 Garden Green Way, Louisville, KY, 40218 \\ Position: Teacher \\ Supervisor: Carletta Bell, M.Ed.
}

Responsibilities: Provided educational services to primary students in grades K-2. Provided behavior services and coordinated with special education teachers to provide accommodations for children with special needs mainstreamed in regular classroom settings. I worked closely with families and the community to acquire additional services for children. Provided leadership to peers as an Accelerated Schools Coach and provided supervision to student teachers from the University of Louisville.

\section{Clinical Experience:}

June 2008-June 2009

\author{
Seven Counties Services, Child \& Family Services \\ 914 East Broadway, Louisville, KY, 40203
}

Responsibilities: Internship responsibilities included training, clinical services, and assessment services for children and their families. I provided individual, group, and family therapy for children, adolescents, and adults in a community mental health 
outpatient center. Specialized training seminars for psychology included assessment, theory, and treatment. Family therapy included specialized training and live supervision.

Supervisors: Tamara Roberts, $\mathrm{PhD}$, David Finke, $\mathrm{PhD}$

Supervised Internship Hours: 1200

June 2008-June 2009 Kentucky Correctional Psychological Center 1612 Dawkins Rd., LaGrange, KY, 40031

Responsibilities: Internship responsibilities included assessment services for inclusion in pre-trial evaluations for the district and circuit courts for the Commonwealth of Kentucky. I participated in training and supervision activities regarding competency to stand trail and criminal responsibility assessments. Reports include information gathered through interview, and formal assessment of psychological symptoms, personality, and malingering.

Supervisors: Steve Simon, $\mathrm{PhD}$, Richard Johnson, $\mathrm{PhD}$

Supervised Internship Hours: 400

June 2008-June 2009 Central State Hospital, Psychology Services

10510 LaGrange Rd., Louisville, KY, 40223

Responsibilities: Internship responsibilities included therapeutic, assessment, and collaboration services for patients in an inpatient psychiatric hospital. Collaboration with a treatment team to determine interventions and assessments needed included psychiatrist, psychologist, nursing, and direct care staff. Individual and group services included symptom management and cognitive behavioral services. Assessments include suicide risk, psychological and personality assessments.

Supervisor: Wayne Putnam, PsyD

Supervised Internship Hours: 200

June 2008-June 2009

Seven Counties Services, Family Preservation Project

914 East Broadway, Louisville, KY 40203

Responsibilities: Internship responsibilities included providing in-home therapeutic services for families of children at risk of removal in Louisville, KY. Services included individual and family therapy, consultation with school teachers and counselors, participation in court proceedings, and support for acquiring community resources.

Supervisor: David Finke, $\mathrm{PhD}$

Supervised Internship Hours: 200 
Responsibilities: Practicum responsibilities are divided between clinical duties and program development. Clinical duties include providing individual, group, and family therapy for children, adolescents, and adults in a community mental health outpatient center. I provide services for the Behavioral Health Child and Family team. Program development and research obligations include grant writing and full program development. Research responsibilities include the development of a study to examine the efficacy of filial therapy with children with Attachment Disorder. This project is the basis for my dissertation.

Supervisor: Elizabeth Jackson, Ph.D. Supervised Practicum Hours: 735

\section{Aug 2004-July 2006 Bellarmine University Counseling Center 2001 Newburg Road, Louisville, KY 40205}

Responsibilities: Provided students (individual, couples and family) with short-term or long-term psychotherapy, identification of transference and counter-transference, clinical conceptualization, identification of dynamics, delivering appropriate interventions, and outreach programming including alcohol abuse, anxiety, depression, date rape, stress relief and sexual orientation issues. Seminars attended included GBLT issues, psychoanalysis, hypnosis, EMDR, and objective relations psychology. Supervision included individual and peer case conference presentations.

Supervisors: Myrna Boland, Psy.D.; Allison From, Psy.D. Supervised Practicum Hours: 1023

\section{Aug 2004- Aug 2005 Louisville Metro Suicide Prevention Coalition Family Health Centers, Inc., 2215 Portland Avenue, Louisville, KY 40212}

Responsibilities: Provided formative evaluations services in the initial stages of development of the coalition. The University of Louisville contingency attended monthly meetings, provided guidance to the committee in the areas of prevention and the proper steps to determine actions. Functions included researching and providing information to the coalition on suicide and depression.

Supervisor: Nancy Cunningham, Ph.D. Supervised Practicum Hours: 104 
Responsibilities: Provided psychological assessment services to adolescents ranging in age from 13 to 19 . Provided cognitive and personality testing and completed extensive psychological assessments. I participated in weekly meetings as a member of an interdisciplinary team which included psychiatrists, psychologists, counselors, and direct care staff. Functions included presentation of psychological assessment reports and to provide input as needed for assessment and clinical concerns.

Supervisor: Russ Williams, Psy.D.

Supervised Practicum Hours: 278

Aug 2003- May 2004

Behavior Associates, Inc. 4846 Ridge Creek Rd., Owensboro, KY 42301

Responsibilities: Provided functional analyses and behavior support plans for individuals with a primary diagnosis of mental retardation. I participated in sixty hours of training in behavior modification and report writing with ResCare, Inc. Duties included client history review, observations, and staff interviews, identification of environmental and behavioral interventions appropriate for clients, training direct care staff, and reports on monthly client progress.

Supervisor: Kai Kirby, Ed.D., Ph.D.

Supervised Practicum Hours: 310

\section{Aug 2001-Dec 2001 \\ Price Elementary, JCPS \\ 5001 Garden Green Way, Louisville, KY, 40218}

Responsibilities: Provided children and their families with counseling services.

Implemented cognitive behavioral therapy including solution focused, role playing, and cognitive restructuring techniques. I consulted with teachers and families to determine access to needed support for children. I provided group therapy, initiated the peermediation program, provided classroom tolerance activities and implemented a school wide campaign on awareness and prevention of alcohol and drug use.

Supervisor: Pam Andrews, Ed. D.

Supervised Practicum Hours: 197

\section{Professional Involvement:}

Kentucky Psychological Association, student member

Early Career Psychologists Committee, 2004-present

Heads Up Kentucky Committee, Nov. 2007-present

Early Career Psychologists Committee, Western Kentucky Rep.

Kentucky Psychological Association of Graduate Students, 2004-present

American Psychological Association, student member, 2004-present 
Kentucky Counselor Association, 2002-2004

\section{University Involvement:}

Doctoral Student Organization, University of Louisville

Student member, 2003-present

Professional Development Chairperson, 2005-2006

\section{Volunteer Work:}

Depression Screenings, University of Louisville

Forum for Youth Violence; Mohammad Ali Institute and University of Louisville Board of Directors, Keneseth Israel Preschool, Louisville, KY

Board Member, Klondike Elementary School; Jefferson County Public Schools, Louisville, KY

Guest Speaker: Immigration, Diversity, and Tolerance; Price Elementary School and Christian Academy; Louisville, KY

\section{Research:}

Research Assistant: Social Information Processing in Juveniles who have Sexually Offended

Supervisor: Patrick Hardesty, Ph.D.

Responsibilities included collecting demographic information, administering assessments, scoring assessments, and reviewing consent and assent with subjects.

Dissertation Topic: Efficacy of Child Parent Relationship Therapy for Caregivers of Children with Attachment Problems.

Supervisor: Dr. Sam Stringfield

\section{Related Information}

\section{Outreach Programs:}

Sergeant, M. \& Steelsmith, L. (2006) Freshman Orientation: Parent Session: How to help your child adjust to the transition. Bellarmine University.

Sergeant, M. (2005) Presentation on alcohol and date rape: How to protect yourself. Bellarmine University, Freshman Student Focus Group.

From, A. \& Sergeant, M. (2005) Residential Advisor Training: Helping Skills, Crisis Intervention, \& Assertiveness. Bellarmine University

Boland, M. \& Sergeant, M. (2005) Faculty presentation on recognizing depression and anxiety in students and the importance of referring students. Bellarmine University. 
Sergeant, M. \& Nordloh, G. (2005) "Buffy, Beer Bad”, Forum with freshman to discuss alcohol related problems and the misperceptions of drinking on campus. Bellarmine University.

Sergeant, M. (2001) Taking Action against Alcohol and Drugs in Schools. Price Elementary, Jefferson County Public Schools.

\section{Group Leader Experience:}

Split Families group: A feelings based group for children dealing with divorced or separating parents. Price Elementary; Louisville, Kentucky.

Anger Management: Coping skills group for children whose anger is causing difficulty functioning. Price Elementary; Louisville, Kentucky.

Peer Mediation: Training to provide peer mediation skills to $4^{\text {th }}$ and $5^{\text {th }}$ grade students. Price Elementary; Louisville, Kentucky.

Protective Parent Group: Working with parents involved with Child Protective Services to accept responsibility and determine needs for parenting. Seven Counties Services; Louisville, Kentucky.

Victims of Domestic Violence and Physical Abuse: An interpersonal therapy group for women who were victims of domestic violence. Seven Counties Services; Louisville, Kentucky.

Sibling Rivalry: Coping skills group for children with sibling rivalry difficulties. Seven Counties Services; Louisville, Kentucky. 